FRANCELIUSA DELYS DE OLIVEIRA

Avaliação da capacidade esteroidogênica dos embriões de preá (Galea spixii): imunomarcação e expressão gênica das enzimas do complexo citocromo P450

São Paulo

2016 


\section{Avaliação da capacidade esteroidogênica dos embriões de preá (Galea spixii): imunomarcação e expressão gênica das enzimas do complexo citocromo P450}

Tese apresentada ao Programa de PósGraduação em Anatomia dos Animais Domésticos e Silvestres da Faculdade de Medicina Veterinária e Zootecnia da Universidade de São Paulo para a obtenção do título de Doutor em Ciências

Departamento:

Cirurgia

Área de Concentração:

Anatomia dos Animais Domésticos e Silvestres

Orientador:

Prof. Dr. Antônio Chaves de Assis Neto

São Paulo 
Autorizo a reprodução parcial ou total desta obra, para fins acadêmicos, desde que citada a fonte.

\section{DADOS INTERNACIONAIS DE CATALOGAÇÃO NA PUBLICAÇÃO}

(Biblioteca Virginie Buff D’Ápice da Faculdade de Medicina Veterinária e Zootecnia da Universidade de São Paulo)

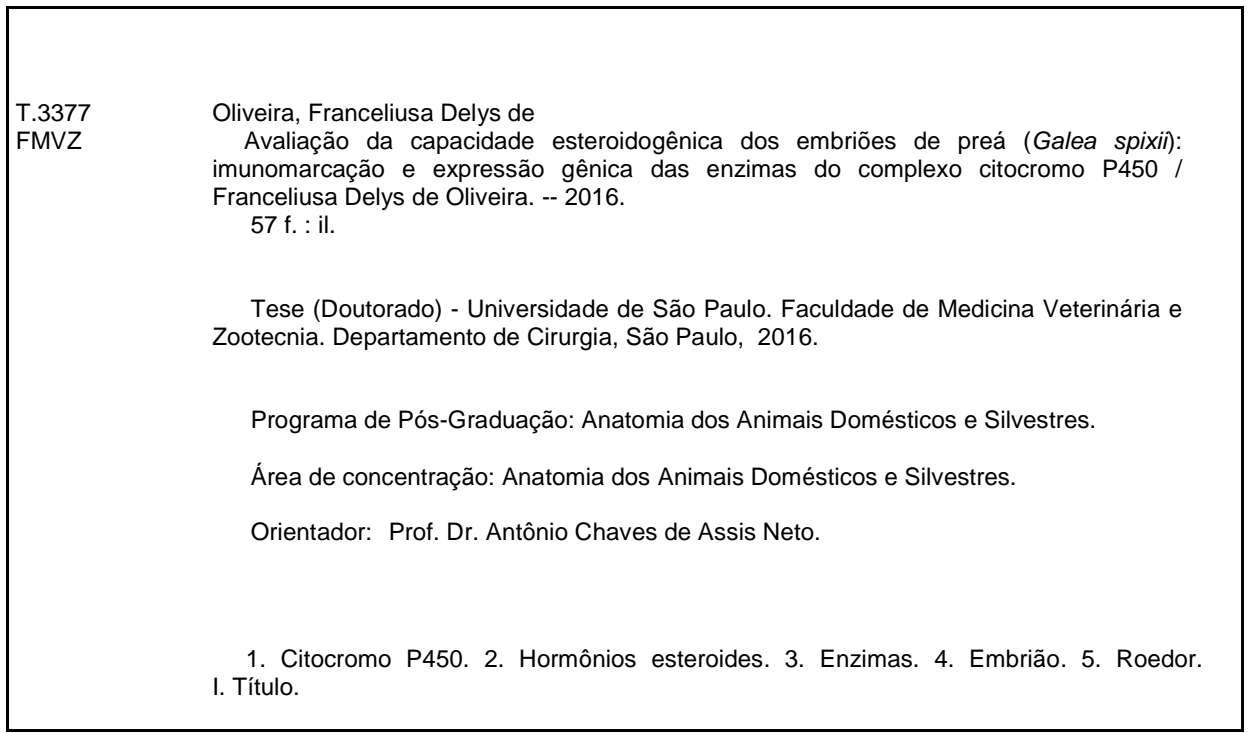




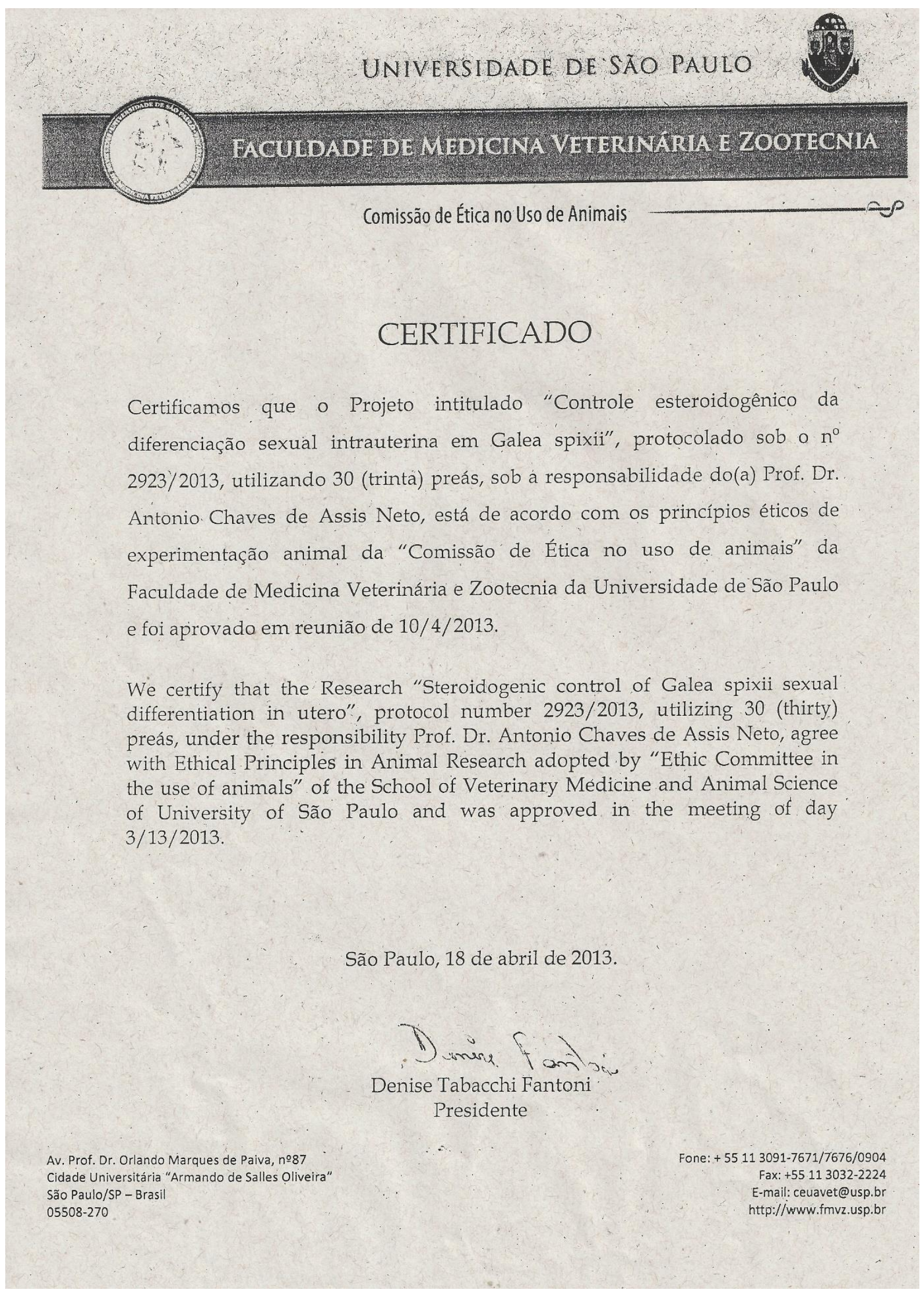




\section{FOLHA DE AVALIAÇÃO}

Autor: OLIVEIRA, Franceliusa Delys de

Título: Avaliação da capacidade esteroidogênica dos embriões de preá (Galea spixii): imunomarcação e expressão gênica das enzimas do complexo citocromo P450

Tese apresentada ao Programa de PósGraduação em Anatomia dos Animais Domésticos e Silvestres da Faculdade de Medicina Veterinária e Zootecnia da Universidade de São Paulo para a obtenção do título de Doutor em Ciências

Data:

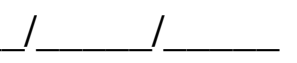

\section{Banca Examinadora}

Prof. Dr.

Instituição: Julgamento:

Prof. Dr. Instituição: Julgamento:

Prof. Dr. Instituição: Julgamento:

Prof. Dr. Instituição: Julgamento:

Prof. Dr. Instituição: Julgamento: 


\section{DEDICATÓRIA}

Dedico este trabalho à toda minha família ...

Minha mãe, Maria Celi

Meu pai, Francisco

Meus irmãos, Mércia e Ricardo

Meus cunhados, Wagner e Ana Lúcia

Meus sobrinhos lindos, Rianni, João Miguel, Maria Luiza e Maria Júlia

Meus avós, tios, primos ...

Esses anos longe de vocês me trouxeram muitos aprendizados, mas nada ficou tão evidente quanto o amor que sinto por todos!!

A minha principal conclusão é que nossa família é o nosso porto seguro; nos bons e maus momentos, nas conquistas e desapontamentos, torcendo pelas nossas vitórias ... são eles que sempre estarão lá e não vão nos decepcionar, jamais.

"Saudade é um pouco como fome. Só passa quando se come a presença. Mas às vezes a saudade é tão profunda que a presença é pouco: quer-se absorver a outra pessoa toda. Essa vontade de um ser o outro para uma unificação inteira é um dos sentimentos mais urgentes que se tem na vida." 


\section{AGRADECIMENTO ESPECIAL}

Faço um agradecimento especial ao meu orientador, Antônio Chaves de Assis Neto.

Obrigada por sempre ter acreditado no meu potencial e colaborado ativamente na produção desse trabalho, sempre buscando fomento e não deixando que nada faltasse para que tudo fosse realizado.

Obrigada por seus ensinamentos, sua atenção, dedicação e amizade que foram determinantes para o bom relacionamento desde o Mestrado, agora no Doutorado e, espero, que por toda nossa vida.

Muito obrigada por tudo ! 


\section{AGRADECIMENTOS}

Aos coordenadores do programa Maria Angélica Miglino e José Roberto Kfoury Júnior pela oportunidade de ingressar na pós-graduação, pelos ensinamentos e por abrirem as portas de seus laboratórios para realização desse trabalho.

Ao Prof. Dr. Moacir Franco de Oliveira por todo auxílio com as coletas dos materiais, por sempre ter me acolhido da melhor maneira no Cemas e na sua própria casa, por todos os ensinamentos e, principalmente, pelo exemplo de professor presente na vida acadêmica e pessoal de seus alunos. Sua participação ativa na execução de cada trabalho servirá de inspiração para quando chegar a minha vez. Valeu muito a pena acordar todos os dias as 5 hs da manhã para fazer citologia, rs.

Aos funcionários do Cemas Seu Almeida, Francisco e (Cuscuz) por todo auxilio com o manejo dos animais.

Aos membros do Comitê de Ética da FMVZ por todo auxílio, prestatividade e agilidade na liberação do certificado.

À Prof. Dra. Paula de Carvalho Papa por permitir acesso ao seu laboratório e uso de equipamentos.

À Prof. Dra. Patrícia Cristina Baleeiro Beltrão Braga por também permitir o uso do seu laboratório e auxílio nos experimentos.

À Elza Faquim pela correção da tese e aos funcionários da secretaria da pósgraduação, Henrique Narducci e Thais Shakushiya, por toda prestatividade e auxílio.

À Dra. Ana Cláudia Carreira que nos ajudou prontamente quanto às dúvidas sobre os experimentos de PCR.

Aos funcionários do setor de Anatomia Ronaldo Agostinho, Jaqueline Martins, André Franciolli, Ednaldo Ribas e Rose Eli pela prestatividade sempre que necessário.

Aos "Assisetes", Antônio Lisboa Neto, Amilton César, Daniela Moraes, Daniela Alcântara, Miguel Lobo, Rodrigo Olivindo por todo companheirismo, conhecimentos compartilhados, journals club. Em especial à Maria Angélica pela amizade e tantos bons momentos compartilhados juntas e, mais em especial ainda, ao Paulo Ramos que se tornou meu parceiro incessante de laboratório, de partidas de vôlei, de Cepeusp, de descargas emocionais. Vocês são muito importantes para mim e por mais que a vida nos leve para caminhos diferentes farei questão de manter nossa amizade viva!

Ao Marcos Vinícius, meu amigo Marcão, gordinho lindo, vida boa ... é difícil descrever o quanto nossa amizade é importante. Desbravamos São Paulo, viajamos juntos, nos divertimos muito, tomamos muitos cafés da tarde, brigamos bastante. 
Essa é sem dúvida uma amizade sem igual! Com você eu pude compartilhar todas minhas angústias, alegrias, decepções da vida na pós-graduação e da vida pessoal. Me disseram que no final eu ia contar nos dedos de uma mão os verdadeiros amigos que eu faria em São Paulo... não tenho dúvidas que você é um deles.

Ao Luciano César, meu parceiro de cinema, de Augusta, de Paulista. Que presente ter conhecido você! Quantas coisas pudemos compartilhar! Você também virou meu confidente, pessoa que eu pude compartilhar tudo desde que nos conhecemos. Nunca nenhum pelo nasceu no meu coração por sua causa e isso mostra como sua amizade é rara.

Ao Prof. Dr. Jodonai Barbosa ou, simplesmente, meu amigo cabeção. Viemos juntos da UFRN para São Paulo (eu, você e a Any Kelly), dividimos quarto e a amizade só cresceu. Você é uma pessoa muito inspiradora, não apenas pelo grande conhecimento científico que tem mas, principalmente, pelo exemplo de coragem, dedicação e esforço. Quando eu crescer quero ser igual a você, rs.

Ao Bruno Bertassoli pelo desenho dos primers, pelas parcerias nos artigos, nos laboratórios mas, principalmente, pela amizade que nem a distância foi capaz de acabar. Os dias em São Paulo se tornaram extremamente divertidos ao seu lado e cada reencontro nosso é motivo de festa. Que permaneçamos assim para sempre!

Às "cajuzetes" Dilayla Abreu e Thais Lessa, minhas morena e loira preferidas. Obrigada pela grande amizade, pelos trabalhos feitos juntas, pelos conhecimentos compartilhados e pelo exemplo de competência e inteligência de ambas.

À Jéssica Borghesi e Lara Carolina pela amizade sincera, por terem compartilhado tantos bons momentos comigo, seja nos laboratórios dividindo nossos conhecimentos ou nos inúmeros passeios e cafés ou ainda em Andradas, me recebendo de braços abertos em suas casas.

À Carla Maria e Adriana Raquel por toda amizade e carinho que sempre tiveram comigo, proporcionando ótimos momentos de convivência dentro e fora dos laboratórios.

Aos alunos do prof. Moacir, em especial à Felipe Venceslau e Radan Elvis por todo o auxílio nas coletas das amostras, por terem me recepcionado tão bem em Mossoró e terem tornado os difíceis dias de coleta tão mais leves e agradáveis.

Ao Cezar Zarza pela amizade, por ser meu psicólogo particular, pela acessoria acadêmica, pelas aulas de Inglês, pela ajuda com os dados estatísticos... Tanta coisa para agradecer só mostra sua importância durante todo esse tempo.

Ao Dr. Rodrigo Barreto por sempre ajudar prontamente quanto às dúvidas sobre os protocolos de PCR.

Aos amigos de pós-graduação Kalena Barros, Diego Muniz, Kátia Guimarães, Aline Poscai, João Leonardo, Fernada Cugola, Cecília Benazzato, Carla Simone, Eduardo Malavasi, Rafael Magdanelo, Renata Avancini, Luiz Nogueira, Rafael Agopian, Bárbara Schäfer, Joice Bertaglia, Flávio Tampinelli, Aline Gonçalves, Renata Silva, 
Bruna Andrade, Dailiany Orechio, Ana Paula Mundim, Paula Fratini, Phelipe Favaron, Patrícia Romagnolli, César Prado, Carol Martins, Diego Curi, Rennan Olio, Juliana Ferrão, Luciana Simões pela amizade e conhecimentos compartilhados e construidos durante o Mestrado e Doutorado.

Às turmas da graduação de Medicina Veterinária da FMVZ 77, 78, 79, 80, 81 e 82 que através das monitorias me proporcionaram muito aprimoramento didático e muito aprendizado em Anatomia.

Às meninas dos times de Vôlei, Handebol e Futsal feminino da Veterinária que me proporcionaram muitos momentos de lazer e divertimento, servindo muitas vezes como uma válvula de escape para os dias estressantes na pós-graduação.

À CAPES e à FAPESP pelo concedimento da bolsa de pesquisa e fomento para a realização deste trabalho.

"Aprenda a gostar, mas gostar mesmo, das coisas que deve fazer e das pessoas que o cercam. Em pouco tempo descobrirá que a vida é muito boa e que você é uma pessoa querida por todos" Rubem Alves 
"A ostra, para fazer uma pérola, precisa ter dentro de si um grão de areia que a faça sofrer. Sofrendo a ostra diz para si mesmo:

'Preciso envolver essa areia pontuda que me machuca com uma esfera lisa que lhe tire as pontas...' Ostras felizes não fazem pérolas... Pessoas felizes não sentem a necessidade de criar. $\mathrm{O}$ ato criador, seja na ciência ou na arte, surge sempre de uma dor. Não é preciso que seja uma dor doída... Por vezes a dor aparece como aquela coceira que tem o nome curiosidade." Rubem Alves, Ostra Feliz Não Faz Pérola 


\section{RESUMO}

OLIVEIRA, F. D. Avaliação da capacidade esteroidogênica dos embriões de preá (Galea spixii): imunomarcação e expressão gênica das enzimas do complexo citocromo P450. [Steroidogenic capacity evaluation of spix yellowtoothed cavy embryos (Galea spixii): immunostaining and gene expression of cytochrome P450 complex enzymes]. 2016. 57 f. Tese (Doutorado em Ciências) Faculdade de Medicina Veterinária e Zootecnia, Universidade de São Paulo, São Paulo, 2016.

A síntese dos hormônios esteroides é feita através da ação de um complexo

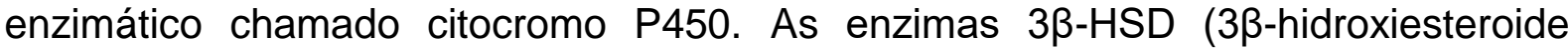
desidrogenase), P450c17 (citocromo P450 17a-hidroxilase/17,20-liase) e P450arom (citocromo P450 aromatase), fazem parte desse complexo e são responsáveis pela síntese dos hormônios progestágenos, andrógenos e estrógenos, respectivamente. Essas enzimas já foram identificadas em inúmeros tecidos, inclusive em embriões em período pré-implantação. Por isso, acredita-se que o blastocisto seja uma fonte de produção de progesterona e estrógeno, hormônios essenciais para implantação e manutenção da gestação. Em roedores, as informações sobre a capacidade esteroidogênica dos embriões são controversas e também restritas apenas a estudos com espécies laboratoriais. Para trazer mais informações sobre a capacidade esteroidogênica em blastocistos de roedores utilizamos o preá (Galea spixii), uma espécie de roedor silvestre encontrada nas regiões de Caatinga e Semiárido do Nordeste brasileiro e muito utilizado na alimentação de famílias de baixa renda como fonte proteica. Diante o exposto, o objetivo deste trabalho é fazer um apanhado histórico sobre os dados publicados a cerca da capacidade dos embriões de diversas espécies de produzir os hormônios esteroides além de identificar e quantificar a expressão das enzimas esteroidogênicas em embriões de preá através das técnicas de imunohistoquímica e PCR em tempo real. As análises morfológicas indicam que o desenvolvimento inicial do preá se assemelha com os demais roedores, porém o tempo de desenvolvimento difere das espécies usadas em laboratório. As marcações da imunohistoquímica foram positivas nos tecidos maternos, mas os embriões não tiveram marcação para nenhuma das três enzimas do estudo. No entanto, os dados obtidos pelo PCR indicam que os genes CYP11, CYP17 e CYP19 foram expressos nos embriões e, portanto, o concepto de G. spixii 
tem capacidade de produzir hormônios esteroides, assim como visto em várias outras espécies que já foram estudadas.

Palavras-chave: Citocromo P450. Hormônios esteroides. Enzimas. Embrião. Roedor. 


\begin{abstract}
OLIVEIRA, F. D. Steroidogenic capacity evaluation of spix yellow-toothed cavy embryos (Galea spixii): immunostaining and gene expression of cytochrome P450 complex enzymes. [Avaliação da capacidade esteroidogênica dos embriões de preá (Galea spixii): imunomarcação e expressão gênica das enzimas do complexo citocromo P450]. 2016. 57 f. Tese (Doutorado em Ciências) - Faculdade de Medicina Veterinária e Zootecnia, Universidade de São Paulo, São Paulo, 2016.
\end{abstract}

The synthesis of steroid hormones is made through the action of an enzyme complex

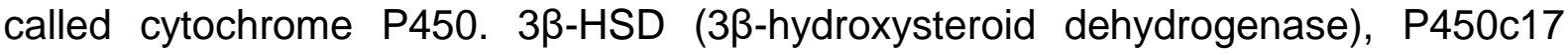
(cytochrome P450 17 a-hydroxylase/17,20-lyase) and P450arom (cytochrome P450 aromatase), are present in this complex and are are responsible for the synthesis of progestins, androgens and estrogens hormones, respectively. These enzymes have been identified in numerous tissues, including embryos in pre-implantation period. Therefore, it is believed that the blastocyst is a source of production of progesterone and estrogen, hormones essential for the implementation and maintenance of pregnancy. In rodents, the information about the steroidogenic capacity of embryos are controversial and confined to studies with laboratory species. To get more information about the steroidogenic capacity in blastocysts of rodents we used the spix yellow-toothed cavy (Galea spixi), a species of wild rodent found in the northeastern of Brazil, and used in the feeding of low-income families as a source of protein. On the above, the aim of this work is to make a historic about the data published about the ability of embryos of various species to produce steroid hormones and identify and quantify the expression of steroidogenics enzymes in embryos of spix yellow-toothed cavy by immunohistochemical and real-time PCR techniques. The morphological analyses indicate that the $\mathrm{G}$. spixii early development resembles other rodents, but development time differs from the species used in laboratory. The immunohistochemical stainning was positive in maternal tissues, but the embryos did not have stainnig for any of the three enzymes of the study. However, the data obtained by PCR indicate that CYP11, CYP17 and CYP19 genes were expressed in embryos and, therefore, the concept of $G$. spixii has capacity to produce steroid hormones, as seen in several other species that have been studied.

Keywords: Cytochrome P450. Steroid hormones. Enzymes. Embryo. Rodent. 
Capítulo 1: o embrião é uma fonte de hormônios esteroides sexuais durante a gestação inicial?

2 INTRODUÇÃO 19

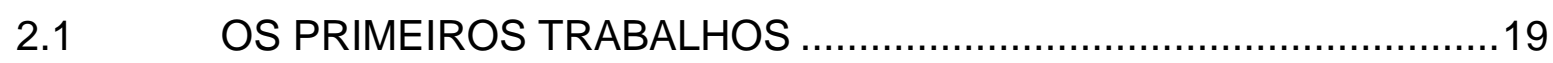

2.2 QUAL A ORIGEM DOS HORMÔNIOS ESTEROIDES SEXUAIS? ......20

2.3 PRESENÇA DOS HORMÔNIOS AO LONGO DO

DESENVOLVIMENTO INICIAL .

2.4 TODOS TECIDOS EMBRIONÁRIOS TEM CAPACIDADE

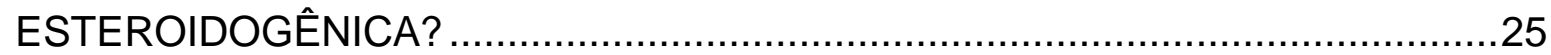

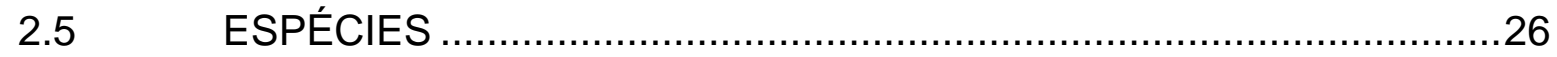

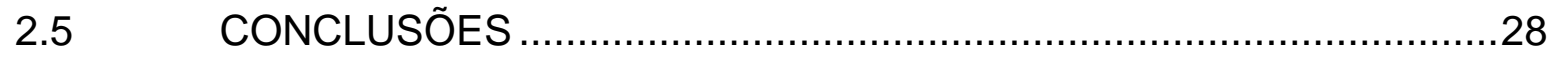

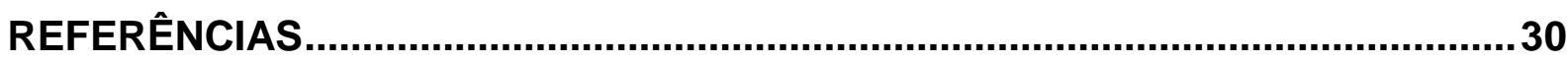

Capítulo 2: AVALIAÇÃO da capacidaDE ESTEROIDOGÊNICA DE EMBRIÕES

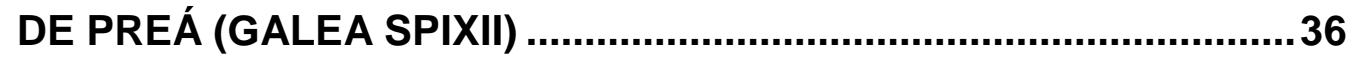

$3 \quad$ INTRODUÇÃO

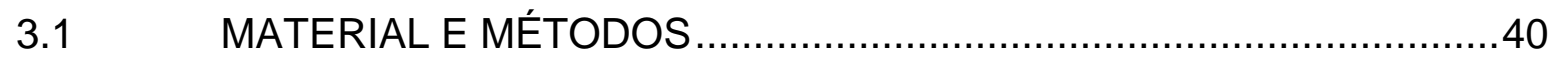

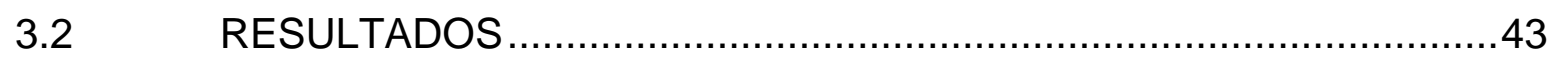

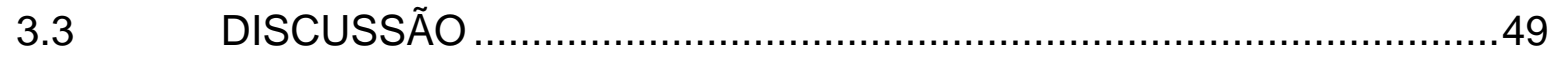

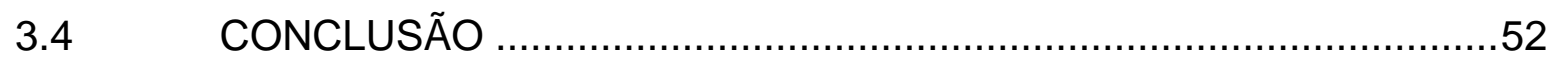

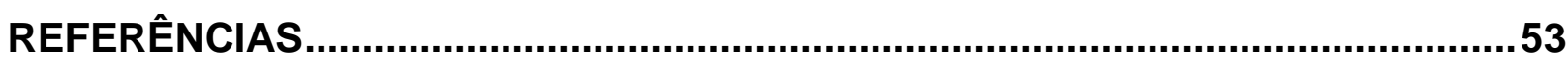

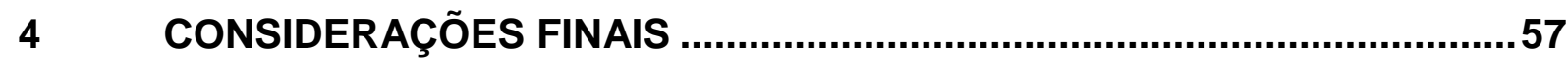




\section{INTRODUÇÃO (GERAL)}

Hormônios são substâncias químicas que agem como mensageiros ou moléculas de sinalização entre órgãos ou células diferentes. De acordo com sua estrutura química eles podem ser classificados como hormônios proteicos, aminoácidos ou esteroides (NORMAN; LITWACK, 1997).

A síntese dos hormônios andrógenos é feita a partir dos hormônios progestágenos, pela ação do complexo enzimático citocromo P450 17ahidroxilase/17,20-liase (P450c17). A enzima 17a-hidroxilase converte a pregnenolona em 17a-hidroxipregnenolona, a qual é convertida em dehidroepiandrosterona pela enzima C17,20-liase. Já a conversão destes hormônios andrógenos em estrógenos é feita através da ação de enzimas chamadas esteroides hidroxilases que são a citocromo P450 aromatase (P450arom) e a citocromo P450 NADPH redutase (redutase). Estas enzimas são codificadas pelo gene CYP19 o qual é altamente conservado em todos vertebrados devido sua função no sucesso reprodutivo das espécies. O que difere é a região promotora, a qual muda de acordo com o tecido onde o gene é expresso, bem como as regiões de éxons que participam da codificação do gene (CONLEY; HINSHELWOOD, 2001; BEM-ZIMRA et al., 2002; SCHULER, 2006).

A enzima citocromo P450arom, responsável por catalisar a reação de conversão dos andrógenos em estrógenos, é expressa em vários tecidos tais como ovários, testículos, tecido adiposo, placenta e em órgãos fetais como fígado e adrenal. Foi demonstrada a expressão da P450arom no trofectoderma do embrião de suínos, equinos e coelhos. Acredita-se que o hormônio produzido pelo próprio embrião seja importante para a implantação, o desenvolvimento fetal, diferenciação neural e do trato reprodutor. No decorrer da gestação os níveis de estrógeno aumentam, porém passam a ser sintetizados pela placenta, mas ainda sim pelas células trofoblásticas (CONLEY et al., 1996).

Sabe-se que para ocorrer uma implantação adequada é necessária a atuação de estrógenos e progesterona, cujas principais fontes são útero e corpo lúteo. Desde a década de 60 que vários estudos começaram a ser realizados no intuito de 
esclarecer se o embrião é capaz de contribuir para o processo de implantação através da produção hormonal. Acreditava-se que o embrião apenas fosse capaz de armazenar os hormônios que são produzidos pelos órgãos genitais maternos e não de produzi-los. Esses estudos apontaram que o embrião, na fase de blastocisto, é sim uma importante fonte de hormônios esteroides, como visto em blastocistos de coelhos e suínos, nos quais a atividade esteroidogênica aumenta com a proximidade do período de implantação. Nestes últimos, os embriões em fase de implantação, entre 10-12 dias, tem capacidade de sintetizar progesterona, 17 $\alpha$-hidroprogesterona 20a-dehidroprogesterona, androstenediona e estrógenos, bem como apresentam atividade das enzimas que catalisam as reações de síntese desses hormônios (PERRY et al., 1973; ANTILA et al., 1977; DICKMANN, 1979; GADSBY et al., 1980; HOVERSLAND et al., 1982; STRÖMSTEDT et al., 1996).

Em trabalhos realizados com blastocistos de ratos, camundongos e hamsters foi encontrada atividade da enzima $3 \beta$-HSD (3$\beta$-hidroesteroide desidrogenase), sugerindo a produção de progesterona por estes embriões. Sendo assim, uma vez que o mecanismo de implantação em roedores é semelhante a essas duas outras espécies, suínos e coelhos, acredita-se que o blastocisto do roedor também seja capaz de produzir hormônios esteroides. Isso foi confirmado em estudos in vitro que mostraram atividade de enzimas esteroidogênicas em mórulas e blastocistos de ratos (ANTILA et al., 1977; DICKMANN, 1979; STRÖMSTEDT et al., 1996).

Ainda assim, a presença das enzimas esteroidogênicas e a síntese de progestágenos e estrógenos nos blastocistos de roedores continuam controversas. Isso porque em estudo realizado por Strömstedt et al. (1996), a expressão dos genes responsáveis por codificar as enzimas esteroidogênicas, especialmente a aromatase, não foi detectada. Esses autores sugeriram que no rato a implantação é dependente somente da progesterona e se algum estrógeno é requerido, apenas o ovário e útero já servem como fontes. Da mesma forma, Antila et al. (1977) viu que blastocistos in vitro em estágio de pré-implantação (3,5 dias) não possuem o mesmo tipo de atividade de enzimas para o metabolismo de esteroides como no coelho e suínos. Outros trabalhos também relatam a falta de atividade esteroidogênica em blastocisto de roedores (GRUBE et al., 1978). Normalmente, os resultados negativos em relação à presença das enzimas no tecido embrionário são atribuídos à baixa 
sensibilidade das técnicas aplicadas ou a pouca quantidade de embriões disponíveis para a pesquisa (GADSBY et al., 1980).

O preá (Galea spixii) é um roedor silvestre encontrado facilmente na região de Semiárido e Caatinga do Nordeste brasileiro. Ele faz parte dos grupos Caviidea, Caviomorpha, Rodentia. Como características morfológicas a espécie apresenta um corpo alongado com tamanho que varia entre $22,5-23,5 \mathrm{~cm}$ e o peso entre $375-405$ g. Na gestação, o número de conceptos é reduzido em relação a outros roedores, variando entre 2-4 filhotes. Durante a reprodução as fêmeas constroem ninhos entre a vegetação e rochas para proteção da sua ninhada. A gestação tem duração de aproximadamente 48 dias, com o desenvolvimento da placenta se iniciando por volta do nono dia. Além de ser o mamífero mais abundante da Caatinga, o preá tem grande importância social para a região uma vez que sua carne é utilizada como fonte de proteína animal entre a população de baixa renda. Ainda, pode ser usado como modelo experimental em pesquisas de interesse médico (OLIVEIRA et al., 2008; OLIVEIRA et al., 2012; SANTOS et al., 2012).

Percebe-se que na literatura os dados sobre a localização e expressão das enzimas esteroidogênicas no período embrionário e, consequentemente, a capacidade deles de produzir hormônios importantes para a implantação são controversos. Além disso, os estudos realizados com roedores tem enfoque em espécies largamente usadas como modelo experimental em laboratório e nenhuma referência são feitas a espécies silvestres de interesse econômico, como os grandes roedores (cutias, paca, capivara e preás). Neste tocante, o presente estudo ajudará a fomentar a hipótese de que o embrião em roedores, com potencial zootécnico já comprovado, são capazes de produzir hormônios tais como estrógenos e progestágenos. Ainda, será importante para o esclarecimento sobre os estágios iniciais de desenvolvimento do preá, uma área que carece de informações descritas na literatura, e compará-la com outras espécies de roedores já conhecidas. 
CAPÍTULO 1: O EMBRIÃO É UMA FONTE DE HORMÔNIOS ESTEROIDES SEXUAIS DURANTE A GESTAÇÃO INICIAL? 


\section{RESUMO}

Uma grande questão na aéra da biologia reprodutiva é o processo de reconhecimento materno da gestação e a manutenção da mesma. Sabe-se que os hormônios esteroides sexuais produzidos pelo organismo materno são essenciais para a sobrevivência e bom desenvolvimento do concepto. No entanto, alguns trabalhos trazem informações que o próprio concepto tem capacidade de sintetizar hormônios progestágenos e estrógenos necessários para o seu desenvolvimento normal intra-uterino. Desde a década de 60 vários autores confirmam a hipótese de que o embrião tem capacidade de produzir hormônios esteroides e os estudos que negam essa hipótese atribuem o resultado à técnicas pouco sensíveis. Percebe-se que essa capacidade varia de acordo com a espécie, sendo amplamente aceita para embriões de coelhos, suínos, equinos e bovinos, enquanto embriões de roedores, por exemplo, essa capacidade é menos explícita.

\section{ABSTRACT}

A big question in reproductive biology is the process of maternal recognition and maintaining of pregnancy. It is known that sex steroid hormones produced by the maternal organism are essential to the survival and development of the fetus. However, some works bring information that the concept itself has the capacity to synthesize progestogens and estrogens hormones necessary for your normal intrauterine development. Since the 60s, various authors confirm the hypothesis that the embryo has the ability to produce steroids hormones and the studies that deny this hypothesis attributed the result to the insensitive techniques. It perceives that this capacity varies according to the species, being widely accepted for embryos of rabbits, pigs, horses and cattle, while rodent embryos, for example, that ability is less explicit. 


\section{INTRODUÇÃO}

Uma das grandes dúvidas na área da biologia da reprodução gira em torno dos mecanismos utilizados na manutenção da gestação. Sabe-se que a formação de um novo indivíduo é um evento que traz muitas modificações ao organismo materno, principalmente os que envolvem os sistemas endócrino e imunológico. Sabe-se também que para o estabelecimento e manutenção da gestação é necessário que o ciclo ovariano esteja funcionando corretamente e que a atividade do corpo lúteo seja prolongada. Porém, em meados do século passado, vários pesquisadores começaram a questionar se apenas o organismo materno é capaz de contribuir com a formação desses hormônios durante a gestação. Será que o próprio concepto tem a capacidade de sintetizar hormônios progestágenos e estrógenos necessários para o seu desenvolvimento normal intra-uterino?

\subsection{OS PRIMEIROS TRABALHOS}

Datam da década de 60 os primeiros trabalhos a tentarem elucidar essa dúvida. Muitos deles se basearam em experimentos com fêmeas ovarectomizadas nos quais a gestação progredia mesmo sem a presença de hormônios esteroides maternos (DEANESLY, 1960). Em outro trabalho, ratas ovarectomizadas receberam mórulas de ratas normais para progressão do desenvolvimento e apenas menos da metade conseguiu chegar ao estágio de blastocisto e, posteriormente, chegar ao período fetal (DICKMANN, 1969); o autor sugeriu então que o embrião é capaz de se desenvolver sem estrógenos e progesterona maternos, porém a presença delas garante uma condição normal de desenvolvimento. Com a publicação de outros trabalhos seguindo a mesma linha com animais ovarectomizados, ficou clara a sugestão que o requerimento hormonal durante a gestação inicial poderia variar de acordo com a espécie. Em coelhas ovarectomizadas e adrenalectomizadas que receberam doses de progestágenos e estrógenos após cirurgia, a progesterona se mostrou ser o hormônio principal na manutenção da gestação e os estrógenos 
pouco influenciam os eventos do período (Kwun \& Emmens, 1974). Huff \& Eik-nes (1966) realizaram uma pesquisa com blastocistos de coelhos com 6 dias de desenvolvimento mantidos em meio de cultura suplementado com vários substratos: progesterona, pregnenolona, 17 $\alpha$-hidroxipregnenolona, androstenediona e acetato de sódio. Como resultado os autores observaram que os embriões foram capazes de metabolizar tais substratos, uma vez que no meio foram encontrados os respectivos produtos. A partir de então, vários outros trabalhos seguiram essa linha de pesquisa, com espécies e idades gestacionais diferentes.

\subsection{QUAL A ORIGEM DOS HORMÔNIOS ESTEROIDES SEXUAIS?}

Hormônios são substâncias químicas que agem como mensageiros ou moléculas de sinalização entre órgãos ou células diferentes. De acordo com sua estrutura química eles podem ser classificados como hormônios proteicos, aminoácidos ou esteroides (NORMAN; LITWACK, 1997). Os hormônios esteroides são produzidos pelas gônadas e também por outras estruturas como a adrenal e placenta. Os principais hormônios esteroides têm na sua estrutura química 3 anéis fenantrênicos (6 carbonos hidrogenados) e mais um anel ciclopentano. Quando a cadeia possui 21 carbonos o hormônio é um progestágenos; se tem 19 carbonos é um andrógeno; e quando a cadeia apresenta 18 carbonos é um estrógeno (HAFEZ; JAINUDEEN; ROSNINA, 2004).

O colesterol é a molécula precursora na formação dos hormônios esteroides. Em todas as células somáticas ele é produzido a partir de moléculas de acetato em uma série de reações que são reguladas pela enzima HMG-coA redutase (PRATT, 1982). O primeiro passo para a formação dos hormônios esteroides é a conversão do colesterol em pregnenolona. Essa reação trata-se da clivagem da cadeia lateral do colesterol pela enzima citocromo P450scc (side chain cleavage cytochrome P450) e necessita ainda do oxigenio atmosférico e de eletrons doados por moléculas redutoras tais como adrenodoxina, redutase de adrenodoxina e NADPH. Como a reação ocorre na crista mitocondrial, sítio da P450scc, o colesterol é transportado até lá pela proteína StAR (Steroidogenic Acute Regulatory protein) (BLACK et al., 
1994; BEN-ZIMRA et al., 2002). A segunda reação ocorre no retículo endoplasmático, onde a pregnenolona é convertida a progesternona pela enzima $3 \beta$ HSD (3ß-hidroxiesteroide desidrogenase) (BORLAND et al., 1977; BEN-ZIMRA et al., 2002). A síntese dos hormônios andrógenos é feita a partir dos hormônios progestágenos, pela ação do complexo enzimático citocromo P450 17ahidroxilase/17,20-liase (P450c17). A enzima 17a-hidroxilase converte a pregnenolona em 17a-hidroxipregnenolona, a qual é convertida em dehidroepiandrosterona pela enzima C17,20-liase. Já a conversão destes em hormônios andrógenos em estrógenos é feita através da ação de enzimas chamadas esteroides hidroxilases que são a citocromo P450 aromatase (P450arom) e a citocromo P450 NADPH redutase (redutase). Um resumo da formação dos principais hormônios esteroides sexuais, desde a formação também do colesterol, pode ser observada na figura 1. Estas enzimas são codificadas pelos genes CYP (CYP11 - P450scc, CYP17 - P450c17, CYP19 - P450arom) os quais são altamente conservado em todos vertebrados devido sua função no sucesso reprodutivo das espécies. O que difere é a região promotora, a qual muda de acordo com o tecido onde o gene é expresso, bem como as regiões de éxons que participam da codificação do gene (CONLEY; HINSHELWOOD, 2001; BEN-ZIMRA et al., 2002; SCHULER, 2006).

A expressão da P450arom está intimamente associada à expressão da citocromo P450 17a-hidroxilase (P450c17) isso ocorre porque a P450c17 cataliza a reação de formação dos andrógenos os quais são os substratos utilizados pela P450arom para sintetizar os estrógenos. Ambas as enzimas formam um complexo com a redutase para que essas reações aconteçam, porém isso não significa que todas são expressas no mesmo tecido ou na mesma célula (CONLEY; HINSHELWOOD, 2001).

A enzima citocromo P450arom, responsável por catalisar a reação de conversão dos andrógenos em estrógenos, é expressa em vários tecidos tais como ovários, testículos, tecido adiposo, placenta e em órgãos fetais como fígado e adrenal (BULUN, 2014). Foi demonstrada a expressão da P450arom no trofectoderma do embrião de suínos, equinos e coelhos. Acredita-se que o hormônio produzido pelo próprio embrião seja importante para a implantação, o desenvolvimento fetal, diferenciação neural e do trato reprodutor. No decorrer da 
gestação os níveis de estrógeno aumentam, porém passam a ser sintetizados pela placenta, mas ainda sim pelas células trofoblásticas (CONLEY et al., 1996).

Figura 1 - Desenho esquemático da formação dos hormônios esteroides sexuais.

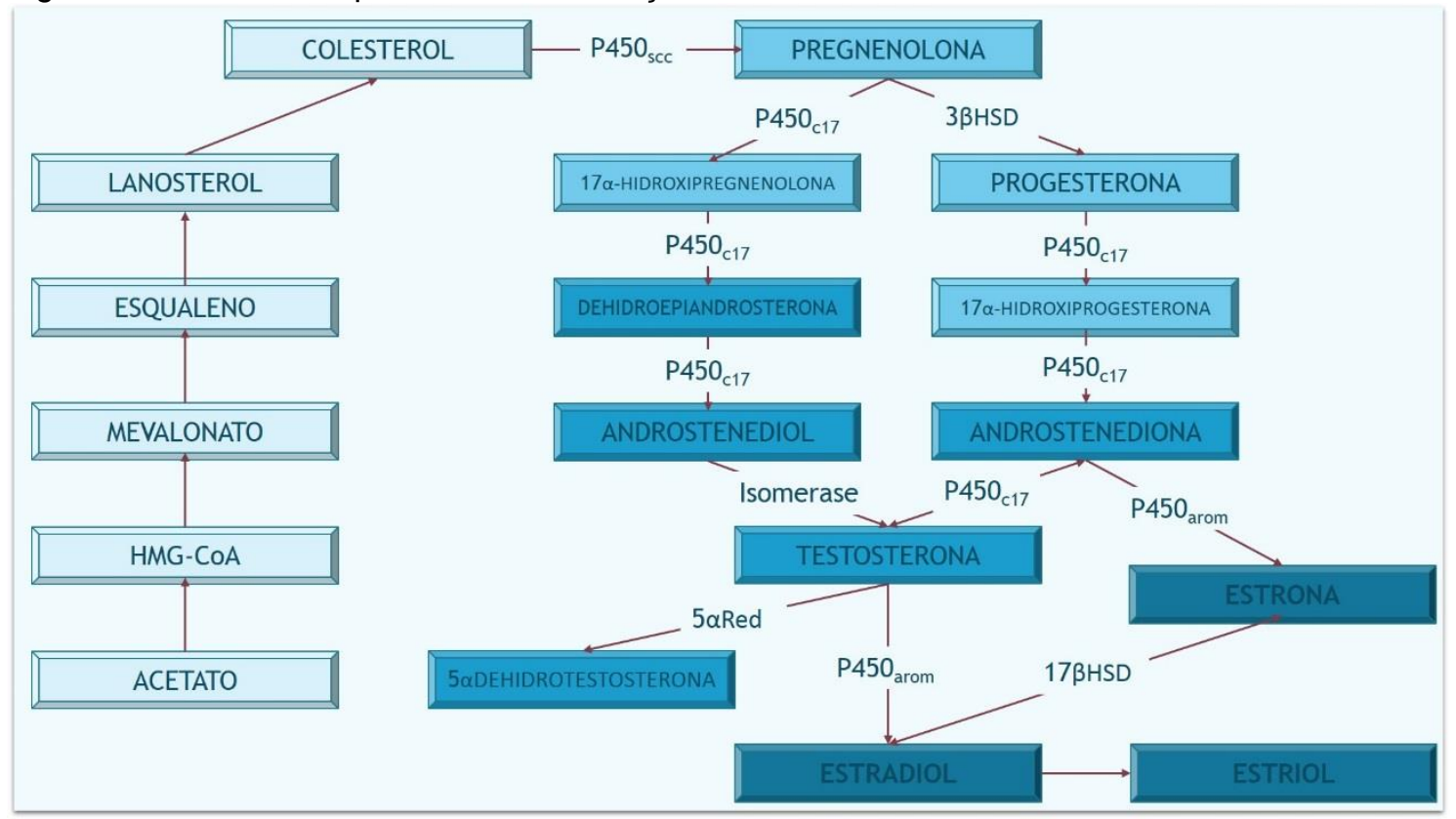

Fonte: Oliveira, F. D., (2016)

\subsection{PRESENÇA DOS HORMÔNIOS AO LONGO DO DESENVOLVIMENTO INICIAL}

Perry et al. (1973) avaliou a produção dos hormônios esteroides em blastocistos de suínos. Esses autores afirmam que os embriões foram capazes de produzir estrógenos (estrona e 17ß-estradiol), progestágenos e esteroides conjugados $e$, consequentemente, inferiram a presença das enzimas esteroidogênicas aromatase, 17-20 desmolase e 3-sulfatase nas células embrionárias. A presença temporal dos hormônios esteroides no embrião inicial também foi avaliada em alguns outros trabalhos. Em mórulas e blastocistos de ratos, verificou-se que níveis crescentes de estrógenos estavam presentes à medida que a mórula se diferenciava em blastocisto e que este se aproximava do período de implantação. Mórulas de 4 dias apresentaram uma atividade maior da enzima $3 \beta$ - 
HSD do que mórulas com 3 dias e, em blastocistos de 5 dias a atividade foi ainda mais acentuada quando comparada a fase anterior (DICKMANN \& DEY, 1974). O mesmo grupo de autores fez trabalho semelhante com embriões de hamsters. Neste foi visto que a atividade da enzima $3 \beta-H S D$ começou no $3^{\circ}$ dia de desenvolvimento

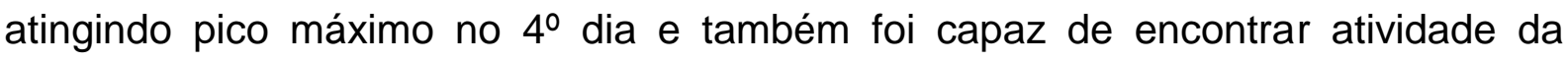
enzima $17 \beta-H S D$ no estágio de mórula. Com isso os autores afirmam que estes embriões tem capacidade de produzir estrógenos necessários para sua diferenciação e implantação no útero (DICKMANN \& GUPTA, 1974). Em outro trabalho, foi visto atividade de hidroxiesteroide dehidrogenases ainda na fase de zigoto de hamsters (NIIMURA \& ISHIDA, 1976). Neste caso, os autores atribuem esse resultado ao tempo que os embriões passaram em incubação e as moléculas usadas como substrato na cultura. Praticamente os mesmos resultados foram observados para mórulas e blastocistos de ratos e coelhos, nos quais ambas enzimas estavam ativas no período pré-implantação (DEY \& DICKMANN, 1974; DICKMANN et al., 1975) e nos coelhos ainda foi identificada a presença da enzima aromatase (formação do $17 \beta$ - estradiol) com pico máximo no sexto dia (HOVERSLAND et al., 1982). Posteriormente, foi visto que a conversão do $17 \beta$ estradiol em estrona aumentava em casos de blastocistos de camundongos no período de implantação sem a presença de hormônios maternos. Isso indica que a atividade da enzima $17 \beta-H S D$ aumenta pois os estrógenos se fazem necessários para o processo de implantação (WU, 1988). A mesma reação ocorre com blastocistos de coelhos, porém nessa espécie a reação contrária, conversão da estrona em 17ß-estradiol, é a que mais prevalece (WU \& WILLIANS, 1989). Além da formação de estrógenos o metabolismo de progestágenos em mórulas e blastocistos de hamster (WU, 1985) e camundongos (WU, 1987) também foi observado . Nestes trabalhos, a progesterona foi metabolizada em basicamente três moléculas, $5 \alpha$ dehidroprogesterona, alopregnenolona e 3a-pregnenolona, indicando a presença das enzimas $5 \alpha$-redutase, $3 \alpha-H S D$ e $3 \beta-H S D$ nos embriões. A capacidade de sintetizar os hormônios esteroides mais tardiamente foi verificada em embriões de camundongo in vitro. Eles conseguem metabolizar pregnenolona e androstenediona em estágios mais avançados de desenvolvimento, por volta do 8-9º dia. Neste trabalho especificamente, os autores não conseguiram identificar o metabolismo destes hormônios nos estágios mais iniciais, porém não descartam a possibilidade, uma vez que a técnica empregada foi diferente da que vinha sendo utilizada pelas 
demais publicações (SHERMAN \& ATIENZA, 1977), observação feita em outros trabalhos (ANTILA et al., 1977). Além de verificar a presença dos hormônios no concepto Dickmann et al. (1977) constataram ainda que o estrógeno produzido pelo blastocisto de rato tinha ação direta no útero, aumentando a permeabilidade capilar local, um evento necessário para a implantação do embrião.

Além dos hormônios progestágenos e estrógenos, os andrógenos também foram estudados, inicialmente em blastocistos de coelho (George \& Wilson, 1978). Neste trabalho, blastocistos no quinto dia de desenvolvimento eram capazes de sintetizar andrógenos e ao sétimo dia, os estrógenos eram produzidos em maior quantidade. Segundo esses resultados, os andrógenos produzidos antes serviriam de substrato para a síntese dos estrógenos no período implantacional.

No fim da década de 70, alguns trabalhos começaram a questionar os resultados que vinham sendo obtidos até então. Em trabalho realizado com embriões de camundongo, Grube et al. (1978) não encontrou diferenças significativas de progesterona e $17 \beta$-estradiol em culturas de mórulas e blastocistos quando comparadas as culturas controles. Também usando cultura, Singh e Booth (1978) não conseguiram detectar síntese de estrógenos, afirmando que esses hormônios, quando encontrados no meio, eram originados da técnica de superovulação adotado nas coelhas. Também em trabalho realizado com injeção de hormônios marcados, esses autores viram que estrógenos injetados em coelhas foram encontrados nos blastocistos, porém advindos do útero, e não produzidos no próprio embrião (SINGH e BOOTH, 1979). Da mesma forma, resultados negativos foram obtidos quando tentaram determinar se o blastocisto de coelho era capaz de sintetizar progesterona a partir da pregnenolona ou androstenediona a partir da dehidroandrosterna, através da ação da enzima $\Delta 5-3 \beta-H S O$ (ANGLE e MEAD, 1979; BLEAU, 1981). Da mesma forma, ao usar inibidores de esteroides, Evans e Kennedy (1980) demonstraram que a implantação do blastocisto de hamster não é diretamente influenciada pelos estrógenos que seriam produzidos pelo embrião; no entanto, no mesmo trabalho, citam que o desenvolvimento da mórula em blastocisto pode ser regulado pelos esteroides produzidos pelo próprio embrião.

Nesses trabalhos, muito se discutiu se esses resultados negativos eram obtidos devido ao fato do embrião de fato não possuir capacidade esteroidogênica 
ou se poderia ocorrer por falta de sensibilidade adequada da técnica. Vários trabalhos comentam que as técnicas histoquímicas, de cultura, recristalização e radioimunoensaio não são tão específicas e podem não ser confiáveis, principalmente, pelo tamanho das amostras dos embriões que são muito pequenas (BLEAU, 1981).

\subsection{TODOS TECIDOS EMBRIONÁRIOS TEM CAPACIDADE ESTEROIDOGÊNICA?}

Além do período de produção dos hormônios, a localização deles também começou a ser avaliada. Inicialmente, foi demonstrado que blastocistos de camundongos eram capazes de converter a pregnenolona em progesterona e que essa capacidade encontrava-se em tecidos embrionários específicos - em células do cone ectoplacentário e células trofoblásticas gigantes. Outros materiais analisados foram as células do próprio embrião, o fluido da blastocele, o fluido uterino, saco vitelino e outros tipos de células trofoblásticas. Desses, o saco vitelino e as demais células do trofoblasto apresentaram níveis basais de atividade da enzima $3 \beta-H S D$, enquanto que nos demais tecidos a progesterona e o estradiol foram facilmente identificados e seus níveis aumentaram gradativamente a medida que os embriões se aproximavam do período de implantação (CHEW; SHERMAN, 1975; SALOMON; SHERMAN, 1975). Porém, quando se analisou os hormônios presentes apenas no embrião, viram que a maior parte deles estavam presentes no fluido da blastocele e não nas células embrionárias (BORLAND et al., 1977). Assim, os pesquisadores começaram a questionar se os hormônios encontrados nos trabalhos anteriores era produzidos mesmo pelo embrião ou advindos do organismo materno, já que nesse período outros órgãos, como a adrenal, são fontes de hormônios esteroides (FUJIMOTO; SUNDARAM, 1978).

Neste mesmo período foram publicados trabalhos que comprovam a importância dos hormônios esteroides para o desenvolvimento adequado do embrião. Com experimentos realizados com embriões de camundongos, Gupta et al. (1976) mostrou que quando os embriões eram tratados com uma substancia anti- 
estrógeno (Cl-628) a diferenciação do zigoto em mórula não foi muito afetada. No entanto, o desenvolvimento da mórula em blastocisto foi bastante afetada, indicando que essa diferenciação inicial é dependente da presença de hormônios estrógenos. Outros trabalhos também utilizando o Cl-628 mostraram que cornos uterinos lavados com tal substancia não apresentavam sítios de implantação quando comparados aos controles, ou que blastocistos incubados com o Cl-628 tinham sua viabilidade diminuída e não eram capazes de se implantar, mostrando que além de participar do desenvolvimento do embrião em si, os estrógenos ainda são necessários para o processo de implantação do blastocisto no útero (BHATT; BULLOCK, 1974; DEY et al., 1976). Quando não prejudicavam o desenvolvimento embrionário como um todo, os inibidores reduziam a produção dos estrógenos e, provavelmente, os andrógenos e outros metabólitos poderiam suprir a necessidade desses hormônios (WU; LIN, 1982). Da mesma forma, quando mórulas de suínos foram cultivadas com uma substância antiestrógeno, a nafoxidina, a diferenciação da mórula em blastocisto foi interrompida, sendo que a cultura com hormônios apresentou um desenvolvimento embrionário adequado (NIEMANN; ELSAESSER, 1986). Isso comprova que a diferenciação inicial do embrião é dependente da presença de estrógenos produzidos ou não pelo próprio embrião.

\subsection{ESPÉCIES}

Até então, as espécies que vinham sendo alvo desses estudos eram sempre de roedores, suínos ou coelhos. Lauria et al. (1979) realizou um estudo para conhecer o comportamento metabólico de mórulas e blastocistos de bovinos e conseguiu confirmar a presença da enzima $3 \beta-H S D$ através de reações histoenzimáticas nestes embriões. Ao analisar a presença dos hormônios esteroides, Shemesh et al. (1979) encontrou progesterona, testosterona e 17 $\beta$ estradiol em culturas de embriões bovinos. O autor sugere ainda que esses hormônios são produzidos mais precisamente pelas células trofoblásticas do embrião, assim como Chenault (1980) que também afirma a presença de vias metabólicas dos esteroides no trofectoderma. O embrião de bovino também foi alvo 
de estudos em idades mais tardias; tanto concepto quanto o endométrio foram capazes de metabolizar progesterona e androstenediona até o D27 (ELEY et al., 1983). Uma vez que foram detectados estrógenos e andrógenos como metabólitos das incubações feitas, presume-se que os embriões bovinos possuam atividade das enzimas 17ß-HSD e da P450aromatase (SHOLL et al., 1983). Outras espécies foram estudadas nesse período tais como ovinos, viscacha, gatos mas os resultados encontrados indicaram que quando comparados aos embriões de suínos, a quantidade de esteroides produzidos nestas espécies ainda é baixa, sugerindo que a produção de estrógenos pelo blastocisto está relacionada a um tipo de implantação mais superficial (GADSBY et al., 1980).

Todos esses trabalhos tinham como foco principal a identificação dos hormônios esteroides ou as enzimas que catalizam a formação deles. Pratt (1982) analisou a capacidade do embrião de camundongo em converter mevalonato em lanosterol - ambos precursores do colesterol - e o lanosterol em colesterol. Ele viu que o período de formação do blastocisto coincide justamente com o período no qual ocorre a formação do colesterol e sugere que, além de compor as membranas das células em formação, esse colesterol servirá também para substrato na esteroidogênese.

Nos trabalhos mais recentes métodos que envolvem biologia molecular foram sendo empregados e muitos continuaram apontando resultados positivos quanto a presença das enzimas e hormônios esteroidogênicos nos embriões. Através da investigação da atividade do RNAm em embriões bovinos, Chiappe et al. (2002) conseguiu identificar atividade da enzima $3 \beta$-HSD em todos os estágios de desenvolvimento, mas principalmente na fase de blastocisto eclodido. Quando se realizou um trabalho removendo um blastômero em murinos, constatou-se que ocorreu uma desregulação do metabolismo esteroide no embrião, principalmente em etapas mais tardias, como na formação da placenta, mostrando que mesmo as células mais iniciais tem importância para a formação dos esteroides no embrião (SUGAWARA et al., 2012). Trabalhos realizados com roedores knockouts mostram que a progesterona tem papel fundamental no desenvolvimento e diferenciação do blastocisto (ZHANG; MURPHY, 2014) e em fases mais tardias do desenvolvimento fetal (GRECO; PAYNE, 1994). A enzima P450arom também foi altamente descrita 
através de técnicas de biologia molecular em suinos e equinos ( $\mathrm{CHOl}$ et al., 1997), assim como o gene da P450c17 (CHU et al., 1999; BAIR; MELLON, 2004)

O fato é que os estrógenos estão relacionados com a implantação do embrião no útero. No local onde isso ocorre, sabe-se que há um aumento na permeabilidade vascular que favorece o processo de implantação e que é medeada pelos estrógenos. Uma vez que essa mudança acontece especificamente, no sítio de implantação, é pouco provável que os estrógenos produzidos pelo organismo materno estejam envolvidos pois eles desencadeariam uma reação em todo endométrio (EVANS; KENNEDY, 1980). Os estrógenos também causam diminuição na quantidade de prostaglandinas produzidas pelo organismo materno, fato importante para a manutenção do corpo lúteo $e$, consequentemente, para a manutenção da gestação com a produção de progestágenos (ELEY et al., 1983). Nas espécies que conseguem manter a gestação mesmo sendo privadas de estrógenos maternos, observa-se que os embriões possuem capacidade esteroidogênica; ao contrário, nas espécies que necessitam de administração dos estrógenos para conseguirem manter o desenvolvimento, o embrião não apresenta essa capacidade, sendo necessários os hormônios de origem materna (SHOLL et al., 1983).

De modo geral, o histórico de trabalhos publicados indica que os embriões no período implantacional tem a capacidade de produzir hormônios esteroides. A produção desses hormônios varia entre as espécies de acordo com o tipo de contato materno-fetal que é estabelecido e também tem variação temporal e na localização das células produtoras. Os resultados negativos encontrados em algumas publicação são atribuídos a problemas com as técnicas empregadas, que podem não ser sensíveis suficientes para detectar as enzimas ou hormônios esteroidogênicos.

\subsection{CONCLUSÕES}

A hipótese de que o embrião tem capacidade de produzir hormônios esteroides é válida e os estudos que negam essa hipótese atribuem o resultado à 
técnicas pouco sensíveis. Percebemos que essa capacidade varia de acordo com a espécie, sendo amplamente aceita para embriões de coelhos, suínos, equinos e bovinos, enquanto embriões de roedores, por exemplo, essa capacidade é menos explícita. Neste caso, a produção hormonal pode estar relacionada com o tipo de implantação do embrião, uma vez que a maioria das espécies com potencial esteroidogênico tem placentação epitéliocorial. 


\section{REFERÊNCIAS}

ANGLE, M. J.; MEAD, R. A. The source of progesterone in preimplantation rabbit blastocysts. Steroids, v. 33, n. 6, p. 625-637. 1979.

ANTILA, E.; KOSKINEN, J.; NIEMELÄ, P.; SAURE, A. Steroid metabolism by mouse preimplantation embryos in vitro. Experientia, v. 33, n. 10, p. 1374-1375. 1977.

BAIR, S. R.; MELLON, S. H. Deletion of the mouse P450c17 gene causes early embryonic lethality. Molecular and Cellular Biology, v. 24, p. 5383-5390. 2004.

BEN-ZIMRA, M.; KOLER, M; MELAMED-BOOK, N.; ARENSBURG, J.; PAYNE, A. $\mathrm{H}$.; ORLY, J. Uterine and placental expression of steroidogenic genes during rodent pregnancy. Molecular and Cellular Endocrinology, v. 187, p. 223-231, 2002.

BHATT, B. M.; BULLOCK, D. W. Binding of oestradiol to rabbit blastocysts and its possible role in implantation. Journal of Reproduction and Fertility, v. 39, p. 65-70. 1974.

BLACK, S. M.; HARIKRISHNA, J. A.; SZKLARZ, G. D.; MILLER, W. L. The mitochondrial environment is required for activity of the cholesterol side-chain cleavage enzyme, cytochrome P450scc. Proceedings of the National Academy of Sciences of the United States of America, v. 91, n. 15, p. 7247-7251, 1994.

BLEAU, G. Failure to detect $\Delta 5-3 \beta$-hydroxisteroid oxidoreductase activity in the preimplantation rabbit embryo. Steroids, v. 37, n. 2, p. 121-132. 1981.

BORLAND, R. M.; ERICKSON, G. F.; DUCIBELLA, T. Accumulation of steroids in rabbit preimplantation blastocysts. Journal of Reproduction and Fertility, v. 49, p. 219-224. 1977.

BULUN, S. E. Aromatase and estrogen receptor $\alpha$ deficiency. Fertility and Sterility, v. 101, n. 2, p. 323-329, 2014.

CHENAULT, J. R. Steroid metabolism by the early bovine conceptus - I. $5 \beta$ reduction of neutral $\mathrm{C}_{19}$ steroids. Journal of Steroid Biochemistry, v. 13, p. 499506. 1980.

CHEW, N. J.; SHERMAN, M. I. Biochemistry of differentiation of mouse trophoblast: $\Delta^{5}, 3 \beta$-hydroxysteroid dehydrogenase. Biology of Reproduction, v. 12, p. 351-359. 1975. 
CHIAPPE, M. E.; LATTANZI, M. L.; COLMAN-LERNER, A. A.; BARAÑAO, J. L.; SARAGÜETA, P. Expression of $3 \beta$-hydroxysteroid dehydrogenase in early bovine embryo development. Molecular Reproduction and Development, v. 61, p. 135141, 2002.

CHOI, I.; COLLANTE, W. R.; SIMMEN, R. C. M.; SIMMEN, F. A. A developmetal switch in expression from blastocyst to endometrail/placental-type cytochrome P450aromatase genes in the pig and horse. Biology of Reproduction, v. 56, 688696. 1997.

CHU, X.; CORBIN, C. J.; KAMINSKI, M. A.; CONLEY, A. J. Unique regulation of CYP17 expression in the trophectoderm of the preattachment porcine blastocysts. Endocrinology, v. 140, p. 632-640. 1999.

CONLEY, A. J.; HINSHELWOOD, M. Mammalian aromatases. Reproduction, v. 121, p. 685-695, 2001.

CONLEY, A. J.; CORBIN, C. J.; HINSHELWOOD, M. M.; LIU, Z.; SIMPSON, E. R.; FORD, J. J.; HARADA, N. Functional aromatase expression in porcine adrenal gland and testis. Biology of Reproduction, v. 54, p. 497-505, 1996.

DEANESLY, R. Implantation and early pregnancy in ovariectomized guinea-pigs. Journal of Reproduction and Fertility, v. 1, p. 242-248. 1960.

DEY, S. K.; DICKMANN, Z. Estradiol-17ß-hydroxysteroid dehydrogenase activity in preimplantation rat embryos. Steroids, v. 24, n. 1, p. 57-62. 1974.

DEY, S. K.; DICKMANN, Z.; GUPTA, J. S. Evidence that the maintenance of early pregnancy in the rabbit requires "blastocyst estrogen". Steroids, v. 28, n. 4, p. 481485. 1976.

DICKMANN, Z. Blastocyst oestrogen: an essential factor for the control of implantation. Journal of Steroid Biochemistry, v. 11, p. 771-773. 1979.

DICKMANN, Z. Hormonal requirements for the transformation of morula to blastocyst in the rat: effects of long-term ovarectomy. Steroids, v.14, n. 4, p. 385-388. 1969. 
DICKMANN, Z.; DEY, S. K. Steroidogenesis in the preimplantation rat embryo and its possible influence on morula-blastocyst transformation and implantation. Journal of Reproduction and Fertility, v. 37, p. 91-93. 1974.

DICKMANN, Z.; DEY, S. K.; GUPTA, J. S. Steroidogenesis in rabbit preimplantation embryos. Proceedings of the National Academy of Sciences of the United States of America, v. 72, n. 1, p. 298-300. 1975.

DICKMANN, Z.; GUPTA, J. S. $\Delta^{5}-3 \beta$-Hydroxysteroid dehydrogenase and estradiol$17 \beta$-hydroxysteroid dehydrogenase activity in preimplantation hamster embryos.

Developmental Biology, n. 40, p. 196-198. 1974.

DICKMANN, Z.; GUPTA, J. S.; DEY, S. K. Does "blastocyst estrogen" initiate implantation? Science, v. 195, p. 687-688, 1977.

ELEY, R. M.; THATCHER, W. W.; BAZER, F. W.; FIELDS, M. J. Steroid metabolism by the bovine uterine endometrium and conceptus. Biology of Reproduction, v. 28, p. 804-816. 1983.

EVANS, C. A.; KENNEDY, T. G. Blastocyst implantation in ovarectomized, adrenalectomized hamsters treated with inhibitors of steroidogenesis during the preimplantation period. Steroids, v. 36, n. 1, p. 41-52. 1980.

FUJIMOTO, S.; SUNDARAM, K. The source of progesterone in rabbit blastocyst. Journal of Reproduction and Fertility, v. 52, p. 231-233. 1978.

GADSBY, J. E.; HEAP, R. B.; BURTON, R. D. Oestrogen production by blastocyst and early embryonic tissue of various species. Journal of Reproduction and Fertility, v. 60, p. 409-417, 1980.

GEORGE, F. W.; WILSON, J. D. Estrogen formation in the early rabbit embryo. Science, v. 199, p. 200-201, 1978.

GRECO, T. L.; PAYNE, A. H. Ontogeny of expression of the genes for steroidogenic enzymes P450 side-chain cleavage, 3 $\beta$-hydroxysteroid dehydrogenase, P450 17 $\alpha$ hydoxylase/c17-20 lyase, and P450 aromatase in fetal mouse gonads.

Endocrinology, v. 135, p. 262-268. 1994. 
GRUBE, K. E.; GWAZDAUSKAS, F. C.; LINEWEAVER, J. A.; VINSON, W. E. Steroidogenic capabilities of the early mouse embryo. Steroids, v. 32, n. 3, p. 345354. 1978.

GUPTA, J. S.; DEY, S. K.; DICKMANN, Z. Evidence that "embryonic estrogen" is a factor which controls the development of the mouse preimplantation embryo.

Steroids, v. 29, n. 3, p. 363-369. 1976.

HAFEZ, E. S. E.; JAINUDEEN, M. R.; ROSNINA, Y. Hormônios, fatores de crescimento e reprodução. In: Reprodução animal. 7. ed. São Paulo:

Manole, 2004. $513 \mathrm{p}$.

HEAP, R. B.; FLINT, A. P. F.; GADSBY, J. E.; RICE, C. Hormones, the early embryo and the uterine environment. Journal of Reproduction and Fertility, v. 55, p. 267275. 1979.

HOVERSLAND, R. C.; DEY, S. K.; JOHNSON, D. C. Aromatase activity in the rabbit blastocyst. Journal of Reproduction and Fertility, v. 66, p. 259-263, 1982.

HUFF, R. L.; EIK-NES, K. B. Metabolism in vitro of acetate and certain steroids by six-day-old rabbit blastocysts. Journal of Reproduction and Fertility, n. 11, p. 5763. 1966.

LAURIA, A.; OLIVA, O.; AURELI, G.; ROGNONI, G. Histochemical demonstration os steroidogenic activity in preimplantation bovine embryos. Annales de Biologie Animale Biochimie Biophysique, v. 19, n. 5, p. 1631-1640. 1979.

KWUN, J. K.; EMMENS, C. W. Hormonal requirements for implantation and pregnancy in the ovarectomized rabbit. Australian Journal of Biological Science, v. 27, p. $275-283.1974$.

MILLER, W. L. Structure of genes encoding steroidogenic enzymes. Journal of Steroid Biochemistry, v. 27, n. 4-6, p. 759-766, 1987.

NIEMANN, H.; ELSAESSER, F. Evidence for estrogen-dependent blastocyst formation in the pig. Biology of Reproduction, v. 35, p. 10-16, 1986.

NIIMURA, S.; ISHIDA, K. Histochemical studies of $\Delta 5-3 \beta-, 20 \alpha-$ and $20 \beta-$ hydroxysteroid dehydrogenases and possible progestagen production in hamster eggs. Journal of Reproduction and Fertility, v. 48, p. 275-278, 1976. 
NORMAN, A. W.; LITWACK, G. Hormones. 2. ed. San Diego: Academic Press, 1997, $558 \mathrm{p}$.

PERRY, J. S.; HEAP, R. B.; AMOROSO, E. C. Steroid hormone production by pig blastocyst. Nature, v. 245, p. 45-47. 1973.

PRATT, H. P. M. Preimplantation mouse embryos synthesize membrane sterols. Developmental Biology, v. 89, p. 101-110, 1982.

SALOMON, D. S.; SHERMAN, M. I. The biosynthesis of progesterone by cultured mouse midgestation trophoblast cells. Developmental Biology, v. 47, p. 394-406, 1975.

SHEMESH, M.; MILAGUIR, F.; AYALON, N.; HANSEL, W. Steroidogenesis and prostaglandins synthesis by cultured bovine blastocysts. Journal of Reproduction and Fertility, v. 56, p. 181-185. 1979.

SHERMAN, M. I.; ATIENZA, S. B. Production and metabolism of progesterone and adrostenedione by cultured mouse blastocysts. Biology of Reproduction, v. 16, p. 190-199. 1977.

SHOLL, S. A.; ORSINI, M. W.; HITCHINS, D. J. Estrogen synthesis and metabolism in the hamster blastocyst, uterus and liver near the time of implantation. Journal of Steroid and Biochemistry, v. 19, n. 2, p. 1153-1161. 1983.

SCHULER, G.; ÖZALP, G. R.; HOFFMANN, B.; HARADA, N.; BROWNE, P.; CONLEY, A. J. Reciprocal expression of 17a-hydroxylase-C17,20-lyase and aromatase cytochrome P450 during bovine trophoblast differentiation: a two-cell system drives placental oestrogen synthesis. Reproduction, v. 131, p. 669-679, 2006.

SINGH, M. M.; BOOTH, W. D. Origin of oestrogen in preimplantation rabbit blastocysts. Journal of Steroid Biochemistry, v. 11, p. 723-728. 1979.

SINGH, M. M.; BOOTH, W. D. Studies on the metabolism of neutral steroids by preimplantation rabbit blastocysts in vitro and the origin of blastocyst oestrogen. Journal of Reproduction and Fertility, v. 53, p. 297-304, 1978. 
SUGAWARA, A.; SATO, B.; BAL, E.; COLLIER, A. C.; WARD, M. A. Blastomere removal from cleavage-stage mouse embryos alters steroid metabolism during pregnancy. Biology of Reproduction, v. 87, n. 1, p. 1-9, 2012.

WU, J. T. Changes in the $17 \beta$-hydroxysteroid dehydrogenase activity of mouse blastocysts during delayed implantation. Biology of Reproduction, v. 39, p. 10211026, 1988.

WU, J. T. Metabolism of progesterone by hamster blastocysts and the ontogeny of progesterone metabolic capability. Biology of Reproduction, v. 33, p. 53-59, 1985.

WU, J. T. Metabolism of progesterone by preimplantation mouse blastocysts in culture. Biology of Reproduction, v. 36, p. 549-556, p. 1987.

WU, J. T.; LIN, G. Effect of aromatase inhibitor on oestrogen production in rabbit blastocysts. Journal of Reproduction and Fertility, v. 66, p. 655-662. 1982.

WU, J. T.; WILLIANS, K. I. H. Metabolism of estrogens by rabbit blastocysts: formation of estrogen glucosides and preferential conversion of estrone to estradiol17ß. Steroids, v. 54, n. 4, p. 401-419, 1989.

ZHANG, C.; MURPHY, B. D. Progesterone is critical for the development of mouse embryo. Endocrine, v. 46, p. 615-623. 2014. 
CAPÍtULO 2: AVALIAÇÃO DA CAPACIDADE ESTEROIDOGÊNICA DE EMBRIÕES DE PREÁ (GALEA SPIXII) 


\section{RESUMO}

Este trabalho objetivou avaliar a capacidade esteroidogênica do embrião de preá (G. spixii) como uma fonte de produção de progestágenos, andrógenos e estrógenos durante o início do período embrionário. Este é um estudo pioneiro, uma vez que utiliza uma espécie de roedor silvestres de interesse econômico e potencial zootécnico. Foram coletados embriões com 7, 8, 10 e 15 dias de gestação, os quais foram fixados em paraformaldeído 4\% para análise morfológica e imunohistoquímica das enzimas P450arom, P450, c17 e P450scc. Outros embriões foram condicionados em RNAlater para extração de RNA para analizar a expressão dos genes que codificam essas enzimas. Além disso, ovários, fígado e adrenais maternos foram coletados para serem tecidos controles e para estudar a dinâmica hormonal durante a gestação inicial. As imunohistoquímicas mostraram que os órgãos maternos apresentam marcação para a aromatase. A P450scc foi vista somente no fígado, enquanto que a P450c17 também teve marcação positiva na adrenal. Os embriões não apresentaram marcação para nenhuma das três enzimas do estudo. As reações de qPCR mostraram que os genes estudados neste trabalhos tiveram sua expressão detectada em todas as idades, exceto o gene CYP11 que não foi expresso no grupo D8. Uma maior expressão dos três genes ocorreu no grupo D7, seguida de uma queda nos dias 8 e 10, e um novo aumento no grupo D15. Com esses dados, podemos confirmar que o embrião do preá (Galea spixii) expressa os genes CYP11, CYP17 e CYP19 no período pós-implantação, indicando a sua capacidade de produzir hormônios esteroides.

\section{ABSTRACT}

This work aimed to evaluate the steroidogenic ability of spix yellow-toothed cavy embryo (G. spixii) as a source of production of progestogens, androgens and estrogens during the beginning of the embryonic period. This is a pioneering study, since it uses a wild rodent specie of economic interest and breeding potential. Embryos were collected with 7, 8, 10, and 15 days of gestation and were fixed in $4 \%$ paraformaldehyde for morphological and immunohistochemical analysis of P450arom, P450c17, and P450scc enzymes. Other embryos were conditioned in 
RNAlater for RNA extraction to analyze the expression of genes encoding these enzymes. In addition, ovaries, liver and adrenals maternal were collected to be controls tissues and to study the hormonal dynamic during pregnancy. The immunohistochemistry showed that all the maternal organs present stainning for aromatase. The P450scc was seen only in the liver, while P450c17 had positive stainnig in adrenal glands also. Embryos showed no stainnig for any of the three enzymes of the study. qPCR reactions showed that genes studied in this work had its expression detected in all ages, except the CYP11 gene that was not expressed in D8 group. Increased expression of three genes occurred in the group D7, followed by a decrease in day 8 and 10, and a further increase in group D15. With this data, we can confirm that the embryo of spix yellow-toothed cavy (Galea spixii) expressed CYP11, CYP17, and CYP19 genes during post-implantation period, indicating their ability to produce steroid hormones.

\section{INTRODUÇÃO}

O preá (Galea spixii) é um roedor silvestre pertencente aos grupos Caviidea, Caviomorpha, Rodentia e é encontrado na região de Semiárido e Caatinga do Nordeste brasileiro. Como características morfológicas a espécie apresenta um corpo alongado com tamanho que varia entre $22,5-23,5 \mathrm{~cm}$ e o peso entre $375-405$ g. Logo, se encontram em uma forma intermediária entre animais do grupo Dasyproctidae, que são maiores, e do grupo Muridae, que são menores. Em relação à morfologia externa, o preá apresenta pelos em todos corpo com coloração variável entre branco (região ventral) e cinza-amarelado (região dorsal). Eles apresentam 3 dedos nas mãos e quatro dedos nos pés e a cauda é inexistente (PERCEQUILLO et al., 2007; OLIVEIRA et al., 2010). Além de ser o mamífero mais abundante da Caatinga, o preá tem grande importância social para a região uma vez que sua carne é utilizada como fonte de proteína animal entre a população de baixa renda. Ainda, pode ser usado como modelo experimental em pesquisas de interesse médico (OLIVEIRA et al., 2008; OLIVEIRA et al., 2012; SANTOS et al., 2012). 
Os hormônios esteroides são produzidos pelas gônadas e também por outros órgãos como adrenal, cérebro, fígado pele, tecido adiposo e placenta (PEZZI et al., 2003; BONDESSON et al., 2014) O primeiro passo para a formação dos hormônios esteroides é a conversão do colesterol em pregnenolona. Essa reação trata-se da clivagem da cadeia lateral do colesterol pela enzima citocromo P450scc (side chain cleavage cytochrome $\mathrm{P450}$ ) e necessita ainda do oxigenio atmosférico e de eletrons doados por moléculas redutoras tais como adrenodoxina, redutase de adrenodoxina e NADPH. Como a reação ocorre na crista mitocondrial, sítio da P450scc, o colesterol é transportado até lá pela proteína StAR (Steroidogenic Acute Regulatory protein) (BLACK et al., 1994; BEN-ZIMRA et al., 2002). A segunda reação ocorre no retículo endoplasmático, onde a pregnenolona é convertida a progesterona pela

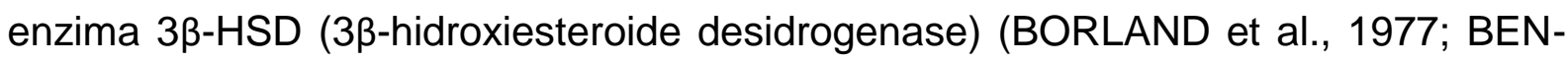
ZIMRA et al., 2002). A síntese dos hormônios andrógenos é feita a partir dos hormônios progestágenos, pela ação do complexo enzimático citocromo P450 17ahidroxilase/17,20-liase (P450c17). A enzima 17a-hidroxilase converte a pregnenolona em 17a-hidroxipregnenolona, a qual é convertida em dehidroepiandrosterona pela enzima C17,20-liase. Já a conversão dos andrógenos em estrógenos é feita através da ação de enzimas esteroides hidroxilases que são a citocromo P450 aromatase (P450arom) e a citocromo P450 NADPH redutase (redutase). Estas enzimas citadas são codificadas pelos genes CYP (CYP11 P450scc, CYP17 - P450c17, CYP19 - P450arom) os quais são altamente conservados em todos vertebrados devido sua função no sucesso reprodutivo das espécies. (CONLEY; HINSHELWOOD, 2001; BEN-ZIMRA et al., 2002; SCHULER, 2006).

A implantação é um evento que necessita de um blastocisto eclodido, isto é, livre de zona pelúcida, e de condições uterinas apropriadas. Sabe-se que durante a implantação são requeridos hormônios esteroides - progestágenos e estrógenos para que ocorra o reconhecimento materno e manutenção da gestação. (ZHANG; MURPHY, 2014; BONDESSON et al., 2015). Esses hormônios são fornecidos pelos órgãos maternos, porém muitos autores afirmam que o próprio embrião é uma fonte desses hormônios (ANTILA et al., 1977; GRUBE et al., 1978; LEVASSEUR, 1984). Mesmo que os eventos bioquímicos e morfológicos que envolvem a implantação variem bastante conforme a espécie, esses hormônios tem papel fundamental na 
gestação inicial dos mamíferos em geral (DICKMANN, 1979). De modo geral, o histórico de trabalhos publicados indica que os embriões no período implantacional tem a capacidade de produzir hormônios esteroides. A produção desses hormônios varia entre as espécies de acordo com o tipo de contato materno-fetal que é estabelecido e também tem variação temporal e na localização das células produtoras. Os resultados negativos encontrados em algumas publicação são atribuídos a problemas com as técnicas empregadas, que podem não ser sensíveis suficientes para detectar as enzimas ou hormônios esteroidogênicos (GRUBE et al., 1978; SINGH; BOTH, 1978; ANGLE; MEAD, 1979; SINGH; BOTH, 1979; EVANS; KENNEDY, 1980; BLEAU, 1981).

Neste tocante, objetivamos avaliar a capacidade esteroidogênica do embrião de preá (G. spixii) como uma fonte de produção de progestágenos, andrógenos e estrógenos durante o início do período embrionário. Como os estudos realizados com roedores tem enfoque em espécies laboratóriais este estudo é pioneiro, uma vez que poucas referências são feitas à espécies silvestres de interesse econômico e potencial zootécnico. Ainda, será importante para o esclarecimento sobre os estágios iniciais de desenvolvimento do preá, uma área que carece de informações descritas na literatura, e compará-la com outras espécies de roedores já conhecidas.

\subsection{MATERIAL E MÉTODOS}

A coleta dos embriões de preá (G. spixii) foi realizada no Centro de Multiplicação de Animais Silvestres (CEMAS) no campus da Universidade Federal Rural do Semi-árido (UFERSA), em Mossoró-RN. Fêmeas e machos em idade reprodutiva foram distribuidos em box, numa proporção de duas fêmeas para um macho. Água e alimentação a base de frutas e vegetais foi dada ad libitum. A partir de então foi realizada citologia esfoliativa vaginal - colpocitologia - em todas as fêmeas para detectar a presença de espermatozoides no trato genital. O dia no qual foi detectada a presença de espermatozoides no trato genital da fêmea foi considerado o dia da cópula (D0) e o dia seguinte como o primeiro da gestação (D1). Nos dias D7, D8, D10 e D15 de gestação as fêmeas foram anestesiadas com 
aplicação de $0,5 \mathrm{ml}$ de cloridrato de xilazina $2 \%$ e a mesma quantidade de cloridrato de cetamina $10 \%$ por via intramuscular. Após a anestesia, os animais foram eutanasiados com aplicação de $1 \mathrm{ml}$ de cloreto de potássio por via intracardíaca. $\mathrm{O}$ útero foi removido e seccionado somente nas regiões onde se encontravam os botões embrionários. Além dos botões embrionários foram coletados ovários, adrenais e fígado maternos para serem usados como controles positivos e para relatar a dinâmica hormonal durante esses períodos. As amostras de cada idade foram divididas para uso nas técnicas de imunohistoquímica e qPCR.

Para a análise morfológica e imunohistoquímica as amostras foram lavadas em PBS antes de serem fixados em solução de paraformaldeido 4\%. Após a fixação, foram desidratadas em série alcoólica crescente, diafanizados em xilol e impregnados com parafina (TOLOSA et al., 2003). Após o processamento as amostras foram cortados em micrótomo Leica RM 2155 (5 $\mu \mathrm{m}$ de espessura) e corados com hematoxilina-eosina. As enzimas analisadas por essa técnica são a P450scc, P450c17 e P450arom. Um par de cortes foram colocados em lâminas silanizadas, foram desparafinados e desidratados e foi feita a recuperação antigênica com tampão de recuperação antigênica pH 6,0 (PMB1-250 - Spring, Fremont, CA) aquecido por 3 minutos em micro-ondas. Foi feito o bloqueio da peroxidase endógena através de imersão em solução de $\mathrm{H}_{2} \mathrm{O}_{2} 3 \%$ e bloqueio de proteínas com a solução Protein Block (DPB-125 - Spring, Fremont, CA). As amostras foram incubadas com anticorpos primários policlonais recombinantes (Abcam, Cambrige, UK) nas diluições mostradas na Quadro 1. O anticorpo primário foi substituído por PBS nos controles negativos. Imunorreatividade foi detectada usando anticorpo secundário (Simple Stain Mouse Max PO - Nichirei Bioscience Inc., Tokyo, Japan) e a revelação foi feita com o sistema DAB substrato (DAB-125 Spring, Fremont, CA). As lâminas foram contra-coradas com hematoxilina e montadas com Permont.

Quadro 1 - Anticorpos e diluições

\begin{tabular}{|l|l|l|}
\hline Anticorpo & Marca (referência) & Diluição \\
\hline Anti-CYP11A1 & Abcam (ab175408) & $1: 50$ \\
\hline Anti-cytochrome P450 17A1 & Abcam (ab48019) & $1: 100$ \\
\hline Anti-Aromatase & Abcam (ab18995) & $1: 50$ \\
\hline
\end{tabular}

Fonte: Oliveira, F. D., (2016) 
As amostras utilizadas para o qPCR foram estocadas em RNAlater (Applied Biosystems, Carlsbad, CA) a temperatura ambiente por uma semana e depois foram congeladas a $-80^{\circ} \mathrm{C}$. A extração do RNA total foi feita com Trizol (Ambion, Carlsbad, $\mathrm{CA})$. À mistura de trizol e tecido foi acrescido clorofórmio e após centrifugação houve separação em três fases. A fase aquosa foi transferida para um novo microtubo, onde foi adicionado isopropanol para precipitação do RNA. O pellet de RNA formado foi ressuspendido em $30 \mu \mathrm{L}$ de água DEPC. A concentração e qualidade das amostras foram verificadas por espectrofotometria (Nanodrop 2000, Thermo Scientific). Em seguida, foi feito o cDNA através da reação de transcriptase reversa utilizando o kit High Capacity cDNA Transcriptase Reversa with Rnase Inhibitor (Applied Biosystems, Carlsbad, CA), como recomendado pelo fabricante. O sistema de detecção escolhido foi o SYBR Green para os genes-alvo CYP11a1, CYP17a1, HSD3B e CYP19a1 (Quadro 2). A reação de PCR foi realizada com o equipamento StepOne Plus (Applied Biosystems, Carlsbad, CA) e foi iniciada pela denaturação à 95으 $\mathrm{C}$ por 10 minutos, seguida por 50 ciclos de: $95^{\circ} \mathrm{C}$ por 10 segundos e $63^{\circ} \mathrm{C}$ por 30 segundos. Oligos para o gene $18 \mathrm{~S}$ foram usados como controle endógeno.

Quadro 2 - Oligonucleotídeos usados para amplificação do cDNA obtido após a reação de transcriptase reversa

\begin{tabular}{|l|l|l|c|}
\hline Gene-alvo (n⿳0 acesso) & Sequencia do primer (5' - 3') & Tm & Produto $(\mathrm{pb})$ \\
\hline CYP11a1 (NM_019779.3) & $\begin{array}{l}\text { F: AGATGCCTGGAAGAAAGACC } \\
\text { R: TGCTGATGGACTCAAAGGAA }\end{array}$ & 63 & 203 \\
\hline CYP17a1 (NM_007809.3) & $\begin{array}{l}\text { F: GCAGAGGTTTGACTTTGATGTG } \\
\text { R: TAAGATTGGGCTGTGGGTGT }\end{array}$ & 63 & 212 \\
\hline CYP19a1 (NM_007810.3) & $\begin{array}{l}\text { F: TGGTGGAAGTTTGTGTGGAG } \\
\text { R: GATGTTTGGTTTGATGAGGAGA }\end{array}$ & 63 & 221 \\
\hline 18S (V01270) & $\begin{array}{l}\text { F:TACCACATCCAAGGAAGGCAGCA } \\
\text { R:TGGAATTACCGCGGCTGCTGGCA }\end{array}$ & 63 & 180 \\
\hline
\end{tabular}

Fonte: Oliveira, F. D., (2016) 


\subsection{RESULTADOS}

Após a remoção do útero foram identificados os botões embrionários de cada idade gestacional. Com apenas uma exceção, em cada fêmea, apenas um embrião havia sido implantado. Observamos que os botões embrionários de 7, 8 e 10 dias apresentaram praticamente o mesmo tamanho; porém de 10 para 15 dias ocorreu um grande aumento, indicando que nesse período ocorre um rápido desenvolvimento do embrião e membranas fetais (Figura 2A).

Microscopicamente vimos que o embrião D10 estava localizado próximo ao lúmen uterino ligado ao endométrio pelo cone ectoplacentário. No endométrio ao redor foi possível distinguir as regiões nas quais estava ocorrendo a reação decidual, a zona externa de reação decidual e a zona interna de reação decidual. $\mathrm{O}$ blastocisto, nesta fase também referido como ovo cilíndrico, estava composto pela cavidade proamniótica a qual formava uma invaginação no ectoderma embrionário. Ao redor dessas células estava localizada uma camada de células endodérmicas embrionárias, contínua com as células do endoderma extraembrionário (Figura 2B). Nessa fase, não foi possível identificar a formação de células mesodérmicas, indicando que com 10 dias o embrião de preá ainda não atingiu a fase de gastrulação, quando os três folhetos embrionários são formados.

No dia 15 foi possível identificamos as membranas embrionárias já bem desenvolvidas. O saco vitelino está presente intimamente associado com o epitélio uterino e apresentou uma camada principal composta pelo endoderma visceral. Neste período o processo de inversão do saco vitelino que ocorre normalmente em roedores já havia ocorrido. Foi possível fazer essa observação pela total ausência da onfalopleura, um tecido justaposto entre o endoderma visceral e o útero (Figura 2C). Dessa maneira o endoderma do saco vitelino se encontrava todo em contato direto com o endométrio, uma condição que permite livres trocas de substâncias entre os tecidos materno e fetal, antes mesmo do estabelecimento definitivo da placenta. O disco embrionário estava em fase trilaminar, ou seja, observamos a presença do três folhetos embrionários e suas primeiras diferenciações. $O$ tubo neural estave totalmente formado, estando transpassado pelo canal neural. Lateralmente ao tubo neural, pudemos observar o mesoderma intra-embrionário 
difernciado em suas três porções: o mesoderma paraxial, ou somitos, mesoderma inteermediário e o mesoderma lateral. Este último apresentava duas camadas distitas: uma em contato com o ectoderma - mesoderma lateral somático - e a outra em contato com o endoderma - mesoderma lateral visceral (Figura 2C).

Figura 2 - Macro e microscopia dos botões embrionários de G. spixii

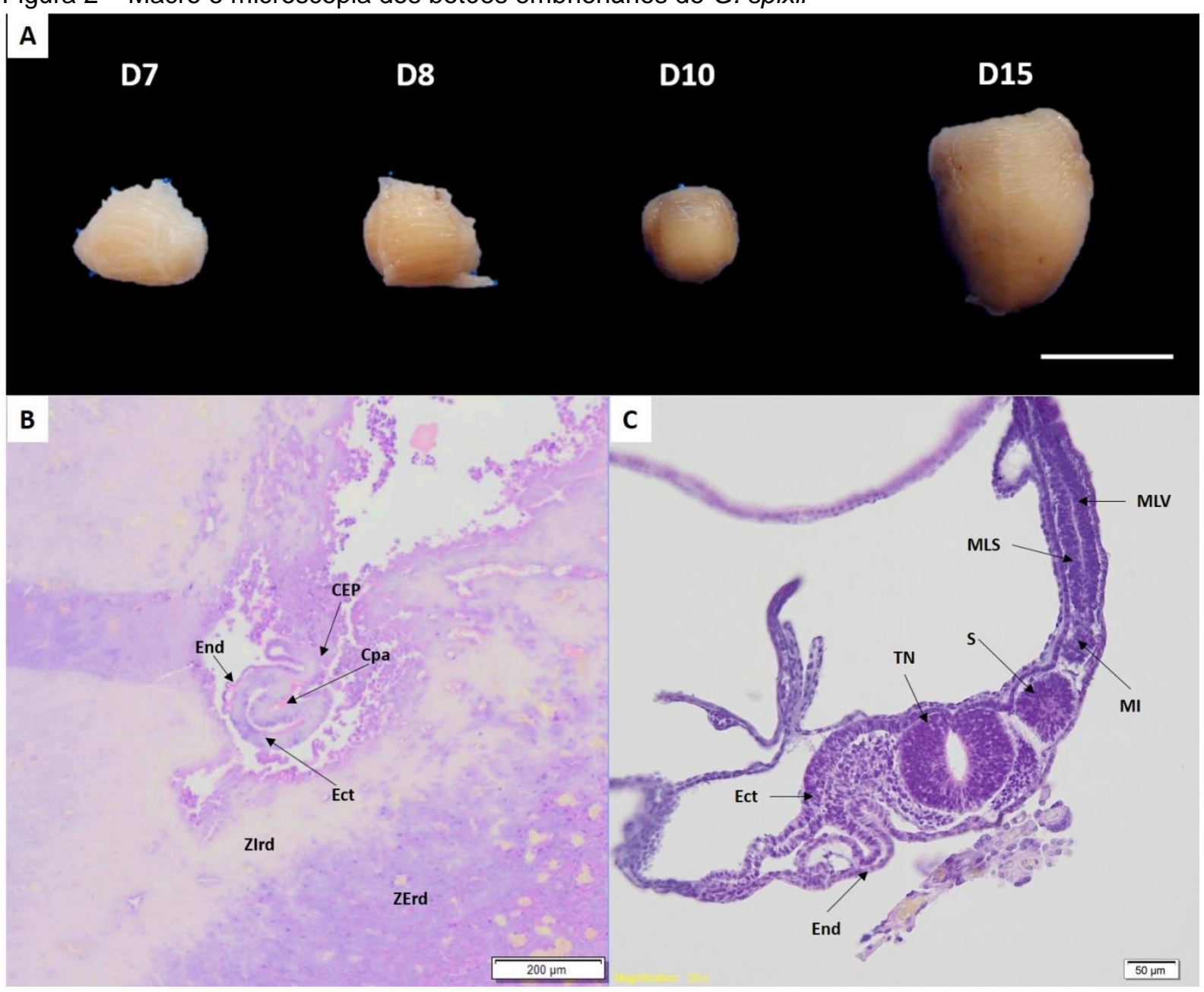

Fonte: Oliveira, F. D., (2016)

Legenda: Em A, botões embrionários removidos dos cornos uterinos. Barra de escala: $1 \mathrm{~cm}$. Em B, fotomicrografia do embrião D10. End - endoderma; CEP - cone ectoplacentário; Cpa cavidade pró-amniótica; Ect - ectoderma; Zird - zona interna de reação decidual; Zerd zona externa de reação decidual. Em C, fotomicrografia do embrião D15. TN - tubo neural; S - somito; MLS - mesoderma lateral somático; MLV - mesoderma lateral visceral; $\mathrm{Ml}$ - mesoderma intermediário.

Em relação aos tecidos maternos coletados, todos apresentaram marcação positiva para imunohistoquímica com o anticorpo P450arom. Nos nossos resultados, não diferentemente do que já foi relatado na literatura, observamos uma marcação 
positiva da P450arom nas células do corpo lúteo e nas células da teca folicular dos ovários em todas idades coletadas (Figura 3A). Logo, uma marcação positiva nas células da teca de fêmeas gestantes pode se um indicativo de que o hormônio produzido pela mãe é necessário ao útero para a manutenção da gestação em curso. O mesmo padrão foi encontrado na marcação da P450arom no fígado. Todas as idades foram positivas na imunohistoquímica, com notável marcação no citoplasma das células dos cordões de hepatócitos (Figura 3C). Na adrenal, ao D10 e D15 de gestação, a marcação foi observada na região cortical da glândula (Figura 3E). Com essa marcação positiva, o fígado e adrenal podem ser considerados órgãos acessórios ao ovário na produção de estrógenos durante a gestação. A marcação da enzima P450scc ficou restrita apenas ao fígado, no qual foi destacada em todo citoplasma dos hepatócitos (Figura 3B). Todas as idades tiveram imunoreatividade para esta enzima, diferentemente dos tecidos ovarianos e adrenais que não foram positivos para a P450scc em nenhuma das idades do trabalho. Já a imunohistoquímica para enzima P450c17 teve marcação positiva no fígado e na adrenal. No fígado (Figura 3D), a enzima estava presente, assim como a P450arom e P450scc, em todo tecido no citoplasma das células hepáticas. Na adrenal (Figura 3F) a distribuição da enzima também foi ampla, sendo encontrada no córtex e na medula, não ficando restrita apenas à região cortical como ocorreu com a P450arom. 
Figura 3 - Imunohistoquímica das enzimas P450arom, P450scc e P450c17 nos ovários, fígados e adrenais maternos

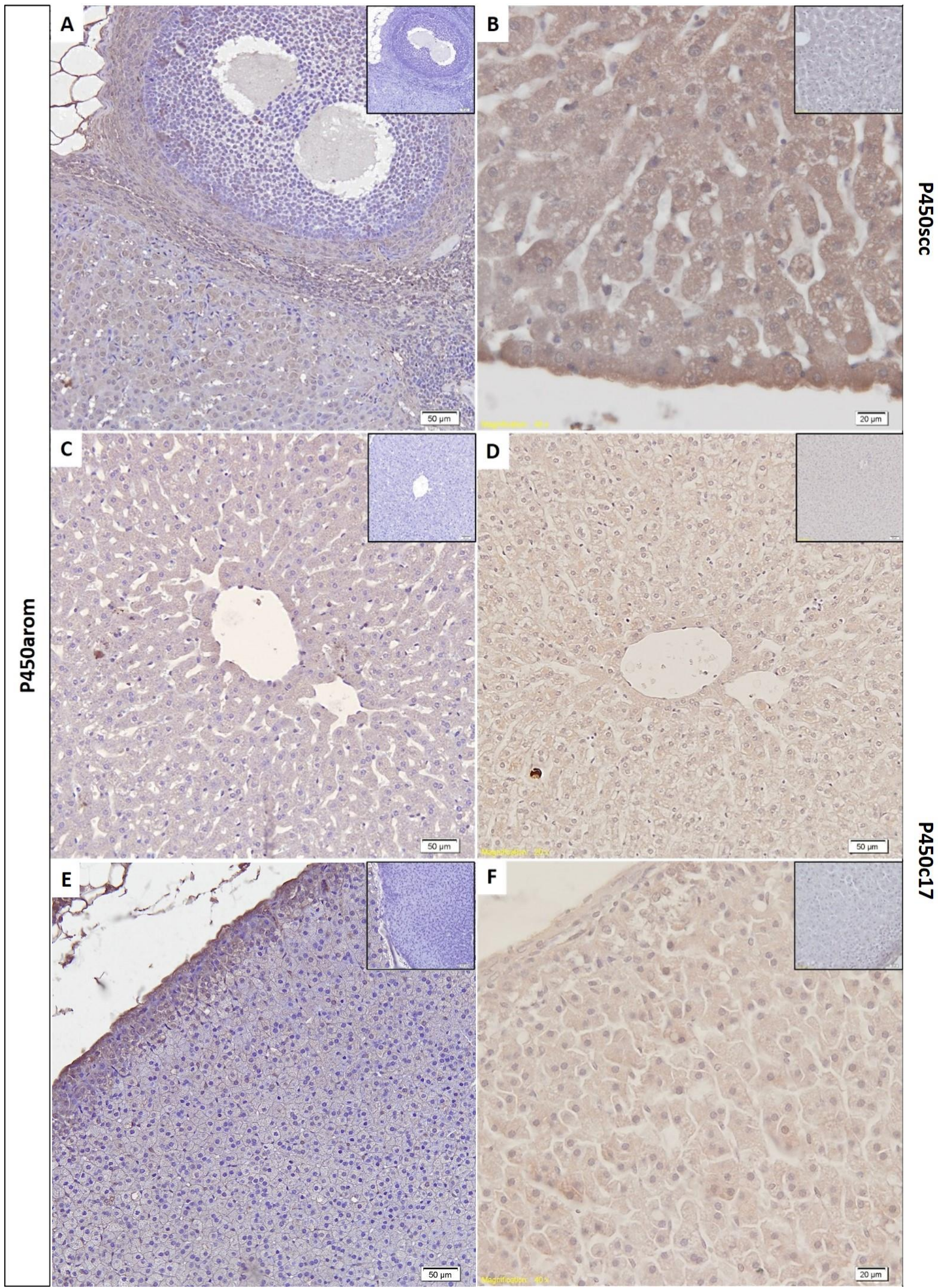

Fonte: Oliveira, F. D., (2016).

Notas: Na canto superior direito de cada imagem uma micrografia dos controles negativos das marcações. 
As imunohistoquímicas foram realizadas nos tecidos embrionários do concepto D15 por já apresentar diferenciação das membranas fetais e disco embrionário e, também, pela dificudade na obtenção de cortes das idades mais iniciais, já que são estruturas de tamanho muito reduzido. Nenhum dos tecidos embrionários - membranas ou disco embrionário - teve marcação positiva para as enzimas do estudo. $\mathrm{Na}$ imunohistoquímica para enzima P450arom foi encontrada marcação positiva no endométrio adjacente ao saco vitelino. Essa marcação foi evidente principalmente próxima aos pequenos vasos sanguíneos, como indicado na figura 4A. Nenhum dos tecidos embrionários do concepto teve marcação para qualquer enzima das três estudadas (Figura 4B), indicando que não há produção de hormônios esteroides pelo embrião nessa idade. Os tecidos maternos de fígado, adrenal e ovário foram usados como controles positivos para as reações das enzimas P450scc, P450c17 e P450arom, respectivamente, como sugerido pelo fabricante dos anticorpos.

Figura 4 - Imunohistoquímica do embrião e membranas fetais D15 para a enzima P450arom

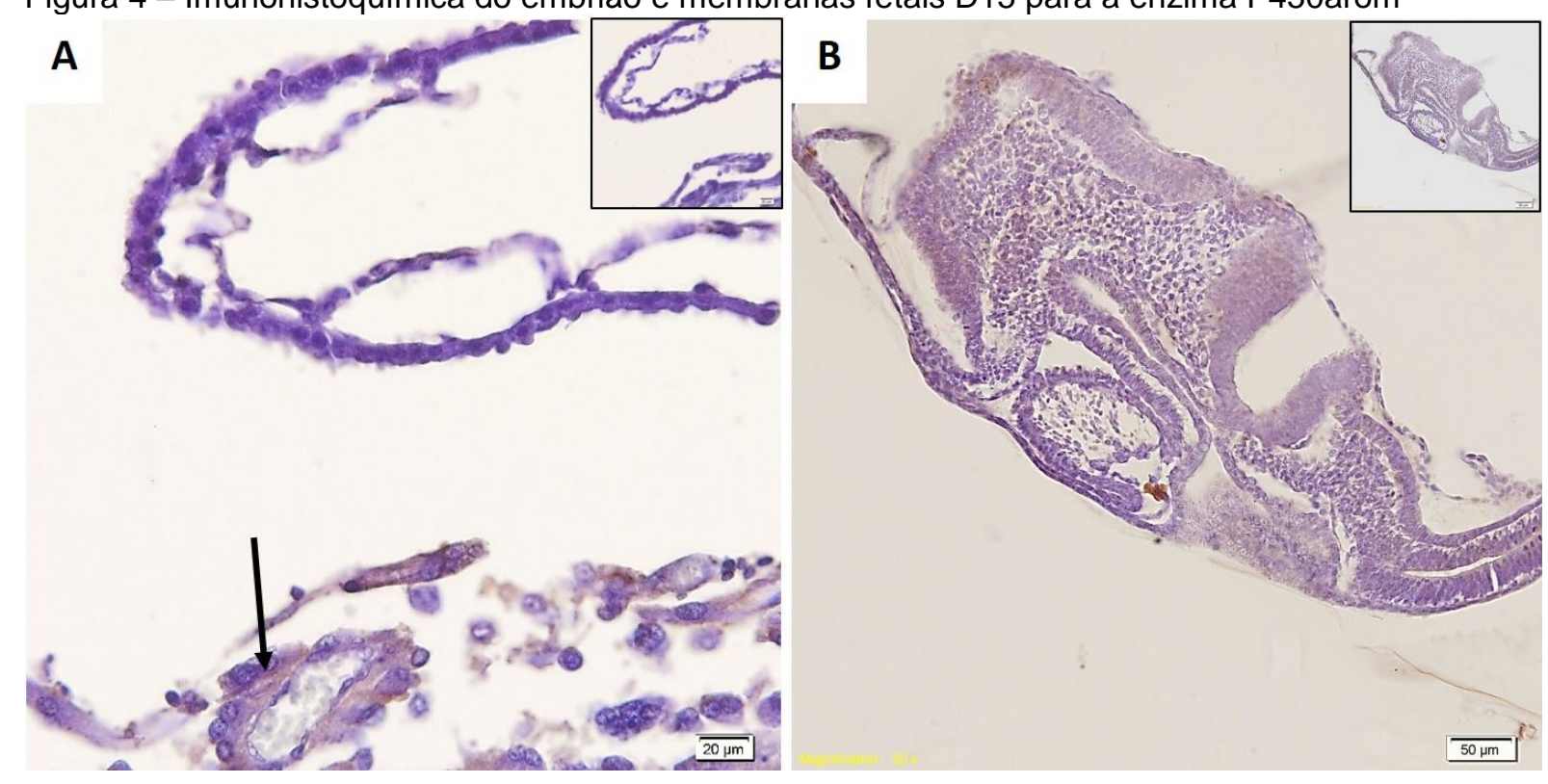

Fonte: Oliveira, F. D., (2016)

Legenda: Em A, seta indica local de marcação positiva no endométrio.

As reações de qPCR mostraram que os genes estudados neste trabalhos tiveram sua expressão detectada em todas as idades, exceto o gene CYP11 que não foi expresso no grupo $\mathrm{D} 8$. De acordo com o cálculo das médias de $\Delta \mathrm{C}_{\mathrm{T}}$ para cada amostra, normalizada com o gene endógeno 18S, vimos que uma maior 
expressão dos três genes ocorreu no grupo $\mathrm{D} 7$, seguida de uma queda nos dias $8 \mathrm{e}$ 10, e um novo aumento no grupo D15 (Tabela 1). Analizando cada grupo isoladamente, temos que com 7 dias, o embrião de preá teve uma maior expressão do gene da P450scc em relação aos genes da P450arom e P450c17. Um padrão semalhante foi encontrado nos embriões D8 e D15, nos quais CYP11 também teve maior expressão, seguida dos genes da P450c17 e P450arom. O único grupo que diferiu desse padrão foi o D10, no qual o gene da aromatase teve maior expressão em relação ao CYP17.

Tabela 1 - Média do $\Delta \mathrm{C}_{\top}$ de cada amostra

\begin{tabular}{l|c|c|c}
\hline Média $\Delta \mathrm{C}_{\mathrm{T}}$ & CYP19 & CYP17 & CYP11 \\
\hline D7 & 13.383 & 13.402 & 16.481 \\
D8 & 6.302 & 8.355 & 10.535 \\
D10 & 7.877 & 5.671 & - \\
D15 & 15.515 & 16.072 & 23.963 \\
\hline
\end{tabular}

Fonte: Oliveira, F. D., (2016) 


\subsection{DISCUSSÃO}

Este trabalho mostra dados pioneiros quanto a morfologia do concepto de roedores silvestres nos estágios iniciais de desenvolvimento, bem como informações sobre a presença das enzimas esteroidogênicas nestes tecidos embrionários. Há muito tempo, vários trabalhos estudam uma possível contribuição do embrião para a composição hormonal no ambiente implantacional, servindo como um indicador para o reconhecimento materno da gestação. Os dados obtidos com esses estudos foram de certa forma conflitantes, com muitos confirmando a hipótese do embrião como um tecido esteroidogênico, enquanto outros não apresentavam fortes evidências para isso. Este trabalho então traz os dados obtidos a partir de uma espécie de roedor silvestre, os quais ainda não tinham sido estudados, e vai ajudar a evidenciar o questionamento quanto à capacidade de produção hormonal pelo embrião.

Em cada gestação apenas um embrião havia sido implantado, com exceção de uma das fêmeas (D15) na qual foram identificados três sítios de implantação. Esse número de embriões está abaixo do relatado para a média descrita para a espécie que é de 2 a 4 embriões por gestação (OLIVEIRA et al., 2008; OLIVEIRA et al., 2012). Como se trata de animais que vivem em cativeiro, essa quantidade reduzida de sítios de implantação pode ser atribuida ao frequente cruzamento parental pelo qual os animais passam. Os botões embrionários coletados aos 7, 8 e 10 dias apresentaram praticamente o mesmo tamanho; porém de 10 para 15 dias, notavelmente, ocorreu um grande aumento no tamanho do botão embrionário, indicando um rápido desenvolvimento do embrião e membranas fetais. Certamente, o disco embrionário apresenta crescimento, porém a diferenciação das membranas embrionárias para a formação inicial da placenta contribui ainda mais para esse rápido desenvolvimento (VALE, 2011).

A morfologia do embrião de 10 dias do preá corresponde ao estágio de desenvolvimento de 5.5 dias visto em ratos e camundongos e mostra que o desenvolvimento inicial do $G$. spixii ocorre em ritmo mais lento, até mesmo devido ao período gestacional mais longo (KAUFMAN, 1992). Durante as coletas de material vimos que com 7 dias de desenvolvimento já encontramos o sítio de implantação, sugerindo que o desenvolvimento do blastocisto em gástrula ocorre, nesse curto 
intervalo de três dias. No dia 15 foi possível identificar as membranas embrionárias já bem desenvolvidas e o processo de inversão do saco vitelino, que ocorre normalmente em roedores, já havia acontecido. Essa inversão do saco vitelino vem sendo alvo de vários estudos e foi vista nessa mesma espécie ocorrendo a partir do 14ํำ dia de gestação (VALE, 2011).

A marcação positiva para a P45arom em todos os tecidos maternos estudados já havia sido observado em outros trabalhos. Na adrenal, a marcação foi observada na região cortical da glândula. Apesar da adrenal ser conhecida principalmente, pela produção de hormônios corticosteroides, sabe-se que ela também tem capacidade de produzir hormônios esteroides sexuais e desempenha papel importante em animais que apresentam sazonalidade em seu ciclo estral. Norman e Litwack (1997) comentam que em humanos, por exemplo, a produção de estriol depende da atividade conjunta de placenta, fígado e placenta. O mesmo padrão foi encontrado na marcação da P450arom no fígado. Com essa marcação positiva, o fígado e adrenal podem ser considerados órgãos acessórios ao ovário na produção de estrógenos durante a gestação também. A literatura reporta sempre como principais sítios de produção desses hormônios a gônada feminina (BONDESSON et al., 2014), porém a presença da P450arom no fígado e adrenal pode ser um indicativo de que essas glândulas possam contribuir com os estrógenos necessários para a manutenção da gestação. Os ovários são reconhecidos por serem as principais estruturas produtoras dos progestágenos e estrógenos (BEMZIMRA et al., 2002; BULUN, 2014). Nos nossos resultados, não diferentemente do que já foi relatado na literatura, observamos uma marcação positiva da P450arom nas células do corpo lúteo e nas células da teca folicular em todas idades coletadas. As células da teca produzem estrógenos, em resposta ao estímulo do hormônio foliculoestimulante (FSH), durante o ciclo estral para que ocorra o desenvolvimento dos folículos ovarianos e consequente liberação do ovócito. Em caso de fertilização, a fêmea entra numa fase de anestro, na qual não ocorre crescimento folicular, uma vez que o organismo materno se prepara para manter a gestação (MCGEADY et al., 2006; MADDOX-HYTTEL et al., 2010). Logo, uma marcação positiva nas células da teca de fêmeas gestantes pode se um indicativo de que o hormônio produzido pela mãe é necessário ao útero para a manutenção da gestação em curso. 
A marcação positiva para a P450scc no fígado e para a P450c17 adrenal já era esperada por se tratarem de tecidos controles nessas reações. A ausência de marcação dessas enzimas nos ovários pode ser um indicativo de um fluxo de formação de hormônios esteroides iniciado no fígado com a conversão do colesterol em pregnenolona, seguido da androgenização na adrenal e finalizada com a aromatização dos andrógenos no ovário. Essa ideia é suportada pelo processo de compartimentalização na produção hormonal, a qual aumenta a eficiência na produção desses hormônios.

Ao analisar as imunohistoquímicas do embrião D15, notou-se que não houve marcação positiva nos anexos embrionários nem no disco embrionário para as enzimas em questão. Uma vez que o trofectoderma é o tecido embrionário comprometido com a formação os tecidos dos anexos embrionários e que segundo a literatura, é o que apresenta capacidade esteroidogênica ( $\mathrm{CHU}$ et al., 1999; WALTERS et al., 2000; CONLEY; HINSHELWOOD, 2001), pode-se presumir que tal capacidade é perdida a medida que o trofectoderma passa por processo de diferenciação. Por outro lado, não foi encontrado na literatura relatos de que as células endometriais tenham maquinaria necessária para formação dos estrógenos, no entanto, a presença dos estrógenos se faz necessária já que são apontados como uma substância inibitória liberada localmente no sítio de implantação para que se inicie um processo inflamatório necessário para a implantação do embrião (DICKMANN, 1979).

A expressão dos genes das enzimas do complexo P450 no preá revela a importância desses hormônios nos processos iniciais de desenvolvimento embrionário. A progesterona e estrógenos, por exemplo, são relacionados ao sucesso na clivagem e diferenciação do blastocisto (HOLDAS, 1993; ZHANG; MURPHY, 2014). Muitos trabalhos relatam a produção dos hormônios esteroides pelo concepto, porém a maioria fez através de técnicas pouco sensíveis, principalmente os trabalhos mais antigos (SALOMON; SHERMAN, 1975; DEY et al., 1976). Os trabalhos mais atuais vem confirmando a a expressão dos genes das enzimas esteroidogenicas nas mais diversas espécies, tornando a informação mais consistente, assim como feito em nosso trabalho (CONLEY et al., 1992; CHOl et al., 1997; CHU et al., 1999; PEZZl et al., 2003; ZHANG; MURPHY, 2014). 
Os hormônios progestágenos são importantes para a manutenção inicial da gestação e os estrógenos atuam como um indicador da presença do embrião ao organismo materno. Mais tardiamente, os genes dessas são altamente expressos nos órgãos endócrinos fetais tais como nas gônadas fetais, durante a diferenciação sexual (GRECO; PAYNE, 1994). Neste período a expressão desses genes já tem uma função voltada especificamente para o desenvolvimento do órgão que o apresenta e não em processos de manutenção da gestação. Essa diferença na expressão e função da enzima ocorre devido a variações na isoformas que são expressas em cada período. Por exemplo, a isoforma do CYP19 expressa no período de implantação difere daquela encontrada durante a formação da placenta apresentando, portanto, funções e níveis de expressão diferentes ( $\mathrm{CHOl}$ et al., 1997).

A falha na detecção das enzimas no embrião podem ser devido à não especificidade do anticorpo usado para a espécie. Apesar de ser um anticorpo policlonal, a nossa espécie de estudo é um animal silvestres e pode ocorrer variações significativas nos epítopos. Mesmo a expressão gênica tendo apresentado resultados positivos, não chega a ser um dado conflitante com a imunohistoquímica, uma vez que os níveis de expressão podem ser baixos e sejam detectados somente através de uma técnica altamente sensível como o PCR. Para solucionar esse questionamento, nos próximos estudos podemos realizar uma quantificação absuluta da expressão em contrapartida da quantificação relativa feita aqui. A presença das enzimas nos tecidos maternos do preá suporta a ideia de que os hormônios produzidos pelo organismo materno e pelo concepto atuam em conjunto para o estabelecimento e manutenção da gestação e para o correto desenvolvimento do embrião nos estágios inicias pós-implantação.

\subsection{CONCLUSÃO}

Podemos confirmar que o embrião do preá (Galea spixii) expressa os genes CYP11, CYP17 e CYP19 no período pós-implantação, indicando a sua capacidade de produzir hormônios esteroides. 


\section{REFERÊNCIAS}

ANGLE, M. J.; MEAD, R. A. The source of progesterone in preimplantation rabbit blastocysts. Steroids, v. 33, n. 6, p. 625-637. 1979.

ANTILA, E.; KOSKINEN, J.; NIEMELA, P.; SAURE, A. Steroid metabolism by mouse preimplantation embryos in vitro. Experientia, v. 33, p. 1374-1375, 1977.

BAIR, S. R.; MELLON, S. H. Deletion of the mouse P450c17 gene causes early embryonic lethality. Molecular and Cellular Biology, v. 24, p. 5383-5390. 2004.

BEN-ZIMRA, M.; KOLER, M; MELAMED-BOOK, N.; ARENSBURG, J.; PAYNE, A. $\mathrm{H}$.; ORLY, J. Uterine and placental expression of steroidogenic genes during rodent pregnancy. Molecular and Cellular Endocrinology, v. 187, p. 223-231, 2002.

BLACK, S. M.; HARIKRISHNA, J. A.; SZKLARZ, G. D.; MILLER, W. L. The mitochondrial environment is required for activity of the cholesterol side-chain cleavage enzyme, cytochrome P450scc. Proceedings of the National Academy of Sciences of the United States of America, v. 91, n. 15, p. 7247-7251, 1994.

BLEAU, G. Failure to detect $\Delta 5$-3 $\beta$-hydroxisteroid oxidoreductase activity in the preimplantation rabbit embryo. Steroids, v. 37, n. 2, p. 121-132. 1981.

BONDESSON, M.; HAO, R.; LIN, C; WILLIANS, C.; GUSTAFSSON, J. Estrogen receptor signaling during vertebrate development. Biochimica et Biophysica Acta (BBA) - Gene Regulatory Mechanisms, v.1849, p.142-151. 2015.

BORLAND, R. M.; ERICKSON, G. F.; DUCIBELLA, T. Accumulation of steroids in rabbit preimplantation blastocysts. Journal of Reproduction and Fertility, v. 49, p. 219-224, 1977.

BULUN, S. E. Aromatase and estrogen receptor $\alpha$ deficiency. Fertility and Sterility, v. 101, n. 2, p. 323-329, 2014.

CHOI, I.; COLLANTE, W. R.; SIMMEN, R. C. M.; SIMMEN, F. A. A developmetal switch in expression from blastocyst to endometrail/placental-type cytochrome P450aromatase genes in the pig and horse. Biology of Reproduction, v. 56, 688696. 1997. 
CHU, X.; CORBIN, C. J.; KAMINSKI, M. A.; CONLEY, A. J. Unique regulation of CYP17 expression in the trophectoderm of the preattachment porcine blastocyst. Endocrinology, v. 140, n. 2, p. 632-640, 1999.

CONLEY, A. J.; HINSHELWOOD, M. Mammalian aromatases. Reproduction, v. 121, p. 685-695, 2001.

DEY, S. K.; DICKMANN, Z.; GUPTA, J. S. Evidence that the maintenance of early pregnancy in the rabbit requires "blastocyst estrogen". Steroids, v. 28, n. 4, p. 481485. 1976.

DICKMANN, J. Blastocyst oestrogen: an essential factor for the control of implantation. Journal of Steroid Biochemistry, v. 11, p. 771-773, 1979.

EVANS, C. A.; KENNEDY, T. G. Blastocyst implantation in ovarectomized, adrenalectomized hamsters treated with inhibitors of steroidogenesis during the preimplantation period. Steroids, v. 36, n. 1, p. 41-52. 1980.

GRECO, T. L.; PAYNE, A. H. Ontogeny of expression of the genes for steroidogenic enzymes P450 side-chain cleavage, 3 $\beta$-hydroxysteroid dehydrogenase, P450 17 $\alpha$ hydoxylase/c17-20 lyase, and P450 aromatase in fetal mouse gonads.

Endocrinology, v. 135, p. 262-268. 1994.

GRUBE, K. E.; GWAZDAUSKAS, F. C.; LINEWEAVER, J. A.; VINSON, W. E. Steroidogenic capabilities of the early mouse blastocyst. Steroids, v. 32, p. 345-354, 1978.

KAUFMAN, M. H. The atlas of mouse development. 2. ed. London: Elsevier Academic Press, 1992. 525 p.

LEVASSEUR, M. The involvement of estradiol at the time of implantation in placental mammals. Animal Reproduction Science, v. 7, p. 467-488, 1984.

MADDOX-HYTTEL, P.; SINOWATZ, F.; VEJLSTED, M. Essentials of domestic animal embryology. London: Saunders Elsevier, 2010. 455 p.

McGEADY, T. A.; QUINN, P. J.; FITZPATRICK, E. S.; RYAN, M. T. Veterinary embryology. lowa: Blackwell Publishing, 2006. 377 p. 
NORMAN, A. W.; LITWACK, G. Hormones. 2. ed. San Diego: Academic Press, 1997. $558 \mathrm{p}$.

OLIVEIRA, G. B.; RODRIGUES, M. N.; SILVA, R. S. B.; PAULA, V. V.; CARVALHO, M. A. M; OLIVEIRA, M. F. Origem e distribuição intraparenquimal da artéria hepática do preá (Galea spixii Wagler 1831). Ciência Animal Brasileira, v. 13, p. 377-381, 2012.

OLIVEIRA, G. B.; RODRIGUES, M. N.; SOUSA, E. S.; ALBUQUERQUE, J. F. G.; MOURA, C. E. B.; AMBRÓSIO, C. E.; MIGLINO, M. A.; OLIVEIRA, M. F. Origem e distribuição dos nervos isquiáticos do preá. Ciências Rural, v. 40, n. 8, p. 1741 1745, 2010.

OLIVEIRA, M. F.; MESS, A.; AMBRÓSIO, C. E.; DANTAS, C. A. G.; FAVARON, P. O.; MIGLINO, M. A. Chorioallantoic placentation in Galea spixii (Rodentia, Caviomorpha, Caviidae). Reproductive Biology and Endocrinology, v. 6, p. 39-46, 2008.

PERCEQUILLO, A.; SANTOS, K.; CAMPOS, B.; SANTOS, R.; TOLEDO, G.; LANGGUTH, A. Mamíferos dos remanescentes florestais de João Pessoa, Paraíba. Biologia Geral Experimental, v. 7, p. 17-31, 2007.

PEZZI, V.; MATHIS, J. M.; RAINEY, W. E.; CARR, B. R. Profiling transcript levels for steroidogenic enzymes in fetal tissues. The Journal of Steroid Biochemistry and Molecular Biology, v. 87, p. 181-189. 2003.

SALOMON, D. S.; SHERMAN, M. I. The biosynthesis of progesterone by cultured mouse midgestation trophoblast cells. Developmental Biology, v. 47, p. 394-406, 1975.

SINGH, M. M.; BOOTH, W. D. Studies on the metabolism of neutral steroids by preimplantation rabbit blastocysts in vitro and the origin of blastocyst oestrogen. Journal of Reproduction and Fertility, v. 53, p. 297-304, 1978.

SINGH, M. M.; BOOTH, W. D. Origin of oestrogen in preimplantation rabbit blastocysts. Journal of Steroid Biochemistry, v. 11, p. 723-728. 1979.

TOLOSA, E. M. C.; RODRIGUES, C. J.; BEHMER, O. A.; FREITAS-NETO, A. G. Manual de técnicas para histologia normal e patológica. 2. ed. São Paulo: Manole, 2003. $331 \mathrm{p}$. 
VALE, A. M. Dinâmica da inversão do saco vitelino em preás Galea spixii Wagler, 1831. 2011. 115 f. Dissertação (Mestrado em Ciência Animal) -

Universidade Federal Rural do Semi-Árido, Mossoró, Rio Grande do Norte, 2011.

WALTERS, K. W.; CORBIN, C. J.; ANDERSON, G. B.; ROSER, J. F.; CONLEY, A. J. Tissue-specific localization of cytochrome P450 aromatase in the equine embryo by in situ hybridization and immunocytochemistry. Biology of Reproduction, v. 62, p. 1141-1145, 2000.

ZHANG, C.; MURPHY, B. D. Progesterone is critical for the development of mouse embryos. Endrocrine, v. 46, p. 615-623. 2014. 


\section{CONSIDERAÇÕES FINAIS}

De modo geral é amplamente aceito que o embrião tem capacidade de produzir hormônios esteroides. De acordo com a espécie a presença dos hormônios e suas enzimas pode variar, inclusive apresentando diferenças entre os tecidos e entre as idades gestacionais. Algumas espécies são reconhecidamente capazes de produzir hormônios esteroides tais como coelhos, suínos, equinos e bovinos, enquanto em embriões de roedores, por exemplo, os dados ainda são controversos. $\mathrm{Na}$ tentativa de auxiliar com mais informações sobre esse tema, este trabalho objetivou avaliar a capacidade esteroidogênica do embrião de preá (G. spixii) como uma fonte de produção de progestágenos, andrógenos e estrógenos durante o início do período embrionário, sendo pioneiro por se tratar de uma espécie de roedor silvestre. Neste caso, vimos que o embrião do preá não apresentou marcação positiva nos testes de imunohistoquímica, porém os dados obtidos com as reações de qPCR mostraram que o embrião contribui para a composição dos hormônios esteroides no período inicial da gestação. Esses são resultados que abrem uma discussão muito mais ampla para melhorar as informações sobre o tema. Por exemplo, fazer uma quantificação absoluta da expressão dos genes-alvo e um sequenciamento dos produtos de reação podem concretizar os resultados obtidos sem deixar dúvidas quanto a expressão das enzimas pelos embriões. Pode ser realizado também um melhor isolamento do embrião e suas membranas fetais, com a utilização de microdissecação, evitando contaminação por tecido materno e diminuindo o viés nos resultados. Todas essa considerações mostram que esse trabalho apresenta várias novas perspectivas para a continuidade do estudo dos hormônios esteroides pelo embrião em desenvolvimento inicial. 